\title{
Sustainable cities: The relationships between urban built forms and density indicators
}

Ehsan Ahmadian ${ }^{\mathrm{a}^{*}}$, Behzad Sodagar ${ }^{\mathrm{a}}$, Glen Mills ${ }^{\mathrm{a}}$, Hugh Byrd ${ }^{\mathrm{a}}$, Chris Bingham ${ }^{\mathrm{b}}$ and Argyrios Zolotas $^{\mathrm{b}}$

\begin{abstract}
The paper introduces a novel indicator of urban built form termed Form Signature. Generic models of four urban built forms are developed, including pavilion, terrace, court and a newly introduced tunnel-court is used to compare and contrast their land-use performance and density characteristics. Selecting plot ratio and site coverage as the most popular and appropriate density indicators, the simultaneous relationship to each of the considered urban built forms is shown graphically with the number of storeys, plan depth and cut-off angle as the main variables of interest. For existing urban areas, the resulting graphs provide a robust tool for statistical analysis of contexts such as climate, economy, energy and crime potential and establish their relationship to form and density. To show the value of the contribution, analysing 32 case studies from 19 cities in different global locations showed an insignificant relationship between climate and form/density of urban areas, whilst practically depicting that urban areas built in court form acquire higher cut-off angle compared to terrace form urban developments. For planning the future urban areas, the resulting relationships provide application-oriented urban planning tool to facilitate the most effective land-use method in order to achieve sustainable cities. Examples showing the potential of the tool for future statistical energy and social analysis of urban areas are provided. Finally, a relative comparison shows that the newly-introduced tunnel-court form achieves the greatest density while pavilion achieves the lowest.
\end{abstract}

\section{Keywords}

Urban built form, density indicators, land-use, urban planning, sustainable cities

\section{Introduction; from morphology to urban policy}

More than $50 \%$ of the world's population live in urban areas, and this is predicted to reach $66 \%$ by 2050 (United Nations, 2014). This rate of urbanization requires a city the size of Birmingham (UK) to be built each week for next 20 years across the globe (Farrell, 2014). The concept of sustainable urban development which requires precise urban planning and land-use management has therefore emerged to ensure sustainable future developments. Whilst in many countries urban policy is based on the development of compact cities as a sustainable urban development (Arundel and Ronald, 2017), many regard expansion of these characteristics to all aspects of sustainability, such as environmental quality, social equity, economic viability, life satisfaction (Du et al., 2017), land use and infrastructure and energy, as vitally important. Alternative studies exist on the perceived advantages of compact cities (Dieleman and Wegener, 2004). Matsumoto et al. (2012) report that compact cities are energetically sustainable since they reduce the energy consumption in the cities (Ewing and Rong, 2008), while others show their relatively low capacity to utilize renewable energy sources such as PVs (Ahmadian et al., 2018, Cheng et al., 2006), ground source heat pumps (Echenique et al., 2012) and biomass solutions (Ghosh et al., 2006), which are considered key technologies of future energy sustainability.

According to literature, many parameters contribute to city forms, i.e. density, compactness, diversity, green areas, orientation, shading, passivity, connectivity, accessibility and centrality. 
Identifying the relationship of energy and urban form, the main parameter analysed by researchers is density (Bhiwapurkar, 2014, Resch et al., 2016, Steemers, 2003). Before establishing the relationship between urban form and density, it is essential to define them. Debating the correlation between "urban form" and "density", different researchers have used a variety of indicators to define density of urban form, leading to confusion. In some cases, opaqueness between the terms "density" and "compactness" also arises. Whilst some studies distinguish between the two (Silva et al., 2017), others use the same indicators to define either compactness (Mohajeri et al., 2016) or density (Sarralde et al., 2015).

This study categorizes density indicators into two main groups, as follows:

1. The first group deals with the physical/geometrical aspects of urban form, such as site coverage, plot ratio (also called floor area ratio (FAR) (Rode et al., 2014) or floor space index (FSI) (Berghauser Pont and Haupt, 2007)), volume-area ratio (Perera et al., 2018), building density, open space ratio (Cheng, 2009), height of buildings, nearestneighbour ratio (Mohajeri et al., 2016), degree of equal distribution "measured by Gini coefficient" (Tsai, 2005), degree of clustering "measured by Moran coefficient" (Tsai, 2005), BPRU index/compactness index (Steadman, 2014a), surface to volume ratio (Ascione et al., 2013, Ratti et al., 2005), volume wall area ratio (Steadman, 2014a, Steadman et al., 2009), urban entropy (Mohajeri et al., 2016), form factor (Coccolo et al., 2016), area of roof to floor area ratio (Byrd et al., 2013) and habitable rooms per hectare (Gordon et al., 2016).

2. The second group not only includes physical characteristics, but also considers population and people behaviour/expectations, thereby bringing social aspects into consideration, such as population density, population-weighted density ( $R, 2014)$ density profile, density gradient (Longley and Mesev, 2002), perceived density (Rapoport, 1975), crowding (Churchman, 1999), living density (Churchman, 1999), occupancy density (Cheng, 2009), gross re-urbanization density (Greenberg, 1991) and jobs per land area.

Comparing results of different case studies using such a diversity of indicators can be challenging. Moreover, sets of indicators tend to closely correlate through basic linear relationships. For example, volume area ratio can be obtained by multiplying plot ratio and the height of each story. Schwarz (2010) empirically analysed the correlation between urban indicators and found seven exhibiting the lowest cross-correlation. Peponis et al. (2007) considered four measures of density (streets, connectivity, population and different building category) for their analysis on the city of Atlanta.

There are also cases of having different indicators referring to the same or similar properties. For instance, the term high density can mean either high building density or high population density. However, higher building density does not necessarily mean higher population density as it depends on other parameters such as building type, mixed land use and the culture of people. In this context, take a small household size case with a large dwelling size, the higher plot ratio may lead to lower occupancy density which means more habitable area for individuals that consequently mitigate the crowding condition (Cheng, 2009). Pointedly in case of energy analysis, given results based on the population density (Arbabi and Mayfield, 2016, Chen et al., 2018, Nichols and Kockelman, 2015) is not sufficient to show the precise relationship of urban density and form with energy. Because most of the calculations of population density are based on an assumption of average number of people per dwelling (Jenks and Dempsey, 2005). Meanwhile, according to parameters such as culture and economic condition, number of people per unit area is not equal in different parts of the world.

To eliminate the effects of people behaviour and social aspects, that are evidently a source of uncertainty in energy analysis (Clevenger and Haymaker, 2006), indicators from the first group 
are used in this study. They are more reliable choice to identify the authentic relationship between urban form and density.

Additionally, building density may be calculated as either gross density (number of dwellings per hectare of a given land area, including public infrastructure such as roads, open space and in some instances non-residential development) or net density (number of dwellings per hectare on land devoted solely to residential development). This could be a useful indicator for making planning policy. In the UK, for instance, the government has set a residential density of 30 dwellings per hectare as the national indicative minimum for new housing developments (DCLG, 2006). This may not however be an optimum density indicator for urban energy analysis (Hamilton et al., 2017) because it does not take into account the form and shape of the buildings that influence the results.

Establishing whether any of the aforementioned indicators represents the true definition of density can be challenging, given that none of those discussed above is sufficiently comprehensive to individually show density of urban form. Hence, a set of indicators should be chosen to define density, and these should have the lowest possible correlation between them. Majority of the mentioned studies have considered only one indicator to show urban density. Even if more than one indicator analysed, no study has examined the effect of urban built form at the same time with density and energy holistically. It is crucial to give information about urban built form as it alters the microclimatic conditions (Emmanuel and Steemers, 2018) that consequently affect building energy consumptions (Lee and Jeong, 2017). There seems to be a lack of a unified set of guidelines to communicate urban density indicators and their relationships with urban built forms. Providing such guidelines is an important contribution of the paper.

Due to the complexity of relationships between form, density and energy, there is no one-sizefits-all solution for optimization (Doherty et al., 2009). Hence, the aim of the study is to develop a series of guidelines to provide a comprehensive relationship of density and four urban built forms in order to assist urban planners on the choice of the most appropriate form and density according to urban policies of cities in different parts of the world. In addition, a new type of built form, termed tunnel-court, is introduced that provides an opportunity for achieving highest urban density and demonstrates the potential for future compact city developments.

This study considers two geometrical density indicators; site coverage and plot ratio, plus three important variables; number of storeys, plan depth and cut-off angle (obstruction angle) that doubtlessly influence the above-mentioned indicators. The analytical and graphical expression of the extensive relationship of these five factors contributes to the future enhancement of this area of study. Analytical models of the different urban built forms considering their land-use performance are used to investigate their inter-relationships with density. The outcome of the analysis allows a direct comparison of the relative attributes of different urban built forms in terms of density, through the introduction of Form Signature, and establishes the relationship between density and urban built dorm used in the wider literature. This comprehensive structure not only proposes a tool for urban design and policy, but also opens a door for future statistical analysis on the relationship of variety of parameters such as energy, climate, family wealth and crime with density and urban built form simultaneously.

The systemic complexity of urban built form is often glided over when policies are formulated. For example, policies to do with interrelated variables such as density, movement, energy and so on; tend to be designed and managed in sequence. This results in "policy silos" that are rarely synthesized and therefore, the reality of cities as complex network of networks, or systematic ecosystems, are unintentionally missed. This has been recognized by several city analysts and observers. For instance: "The point is that planners do not sit above the system, bending it to their will: cities are complex, emergent patterns that result from the interaction of a huge number of variables, including society's norms and values, the working of markets 
and the impact of technology. Planning is just one of the inputs to the system, and probably not the most important one." (Rudlin, 2019). The importance of this work regarding urban planning and policy is two-fold. Firstly, the ease of using the proposed graphical tool for future planning and policy that addresses the balance between influential variables following existing restrictions inherited from the concept of Form Signature. Secondly, this publication can be adopted as a baseline for future urban assessments specifically for investigating relationships of energy with density and form to advice policy makers for performing application-oriented urban planning i.e. energy-oriented urban planning.

Although mainly energy analysis in the cities mentioned above, this study identifies a procedure for bringing into equation other parameters such as climate, economy and social issues as cities are ecosystems (Newman and Jennings, 2012) that require sustainability in all these components.

\section{Research methodology and materials}

For this research, generic models of four urban built forms are developed in order to define the true relationship of "urban built form" and "density" for various cases. Three of them (pavilion, terrace and court form) are the elementary forms developed by (March, 1972), and widely used by many authors (Huang et al., 2008, Ratti et al., 2003). They may be found in different places of the world albeit slightly amended with reference to culture and climatic condition. The fourth built form, termed a "tunnel-court", is developed in this study, based on an amended and practical version of the "cruciform" developed by (March, 1972). These theoretical models drive the equations that govern the correlation between indicators.

\subsection{Geometrical parameterization of urban built forms}

A site with generic area, Z, is considered to set a threshold for the built area (Figure 1).

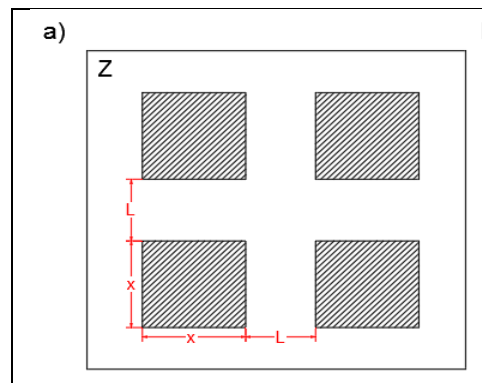

c)

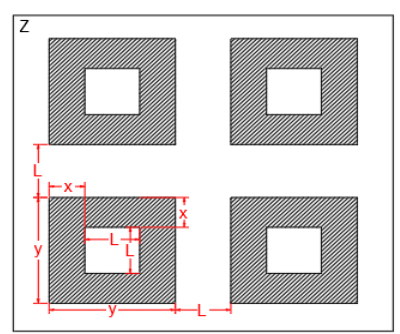

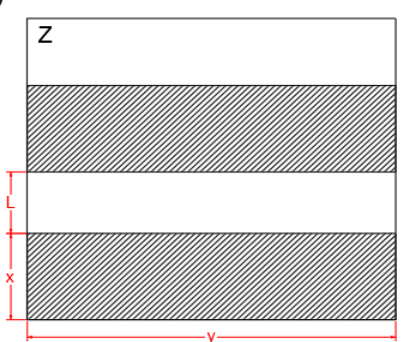

d)

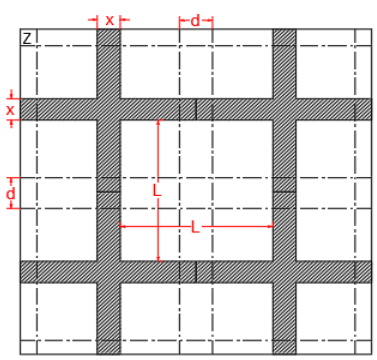

Site plans

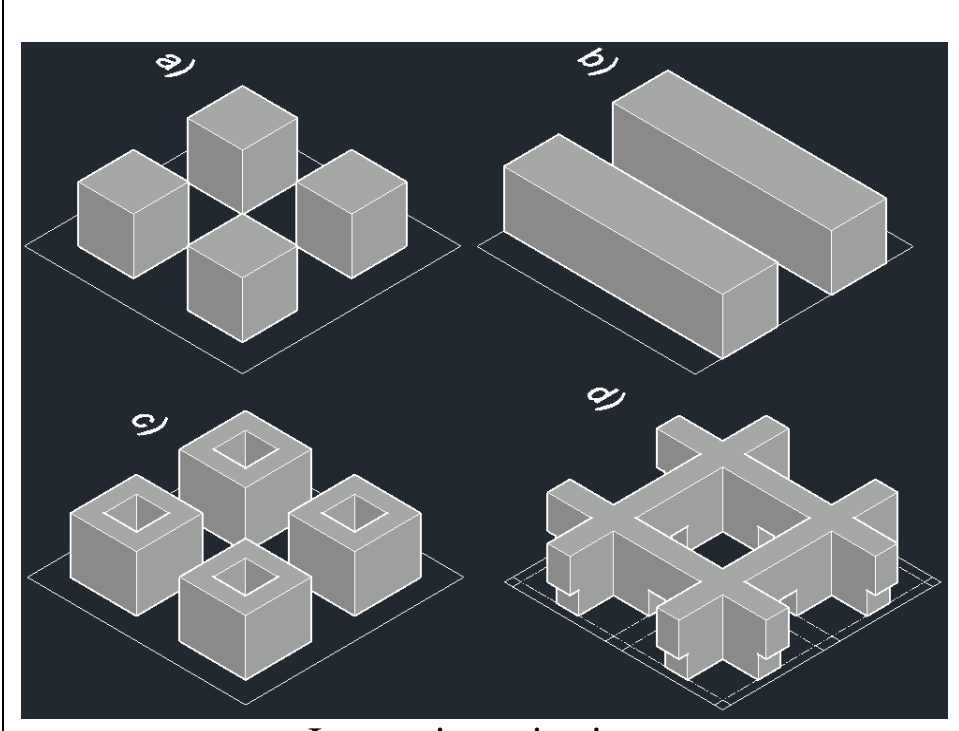

Isometric projections 


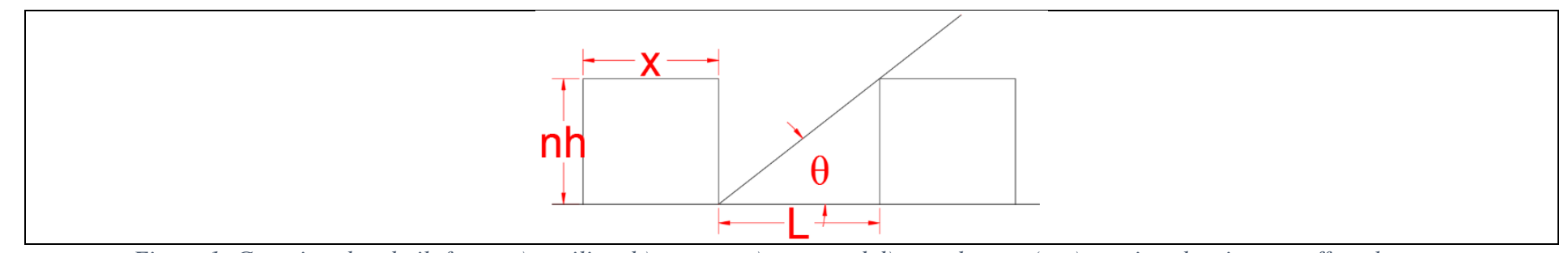

Figure 1: Generic urban built forms a) pavilion, b) terrace, c) court and d) tunnel-court (top), section showing cut-off angle (down)

The main indicators to be examined are:

- Site coverage $(C)$ : defined as $\frac{\text { total built area (covered by buildings) }}{\text { total area of site }}$

- Plot ratio $(P)$ : defined as $\frac{\text { total floor area }}{\text { total area of site }}$

The density gradient (which shows the rate at which density falls from the location of reference) of the whole site is zero since the buildings are evenly distributed over the entire area.

Parameters that can affect the results of subsequent analysis are:

- Number of storeys $(n)$

- Storey height $(h)$

- Cut-off angle or obstruction angle $(\theta)$ (is the angle between the ground and the line joining the roofline of one façade to the base of another façade) (Figure 1(down))

- Plan depth $(x)$

- Distance with adjacent building $(L)$

The height of building is simply calculated using equation (1),

$$
H=n h
$$

The cut-off angle is calculated using equation (2),

$$
\tan \theta=\frac{n h}{L}
$$

Hence, the distance between two buildings $(L)$ is dependent on cut-off angle, as follows:

$$
L=\frac{n h}{\tan \theta}
$$

\subsubsection{Pavilion, terrace and court forms (Figure $1 a, b$ and $c$ )}

From Figure 1, the number of building blocks $\left(m_{b}\right)$ is calculated by dividing the whole area of site (Z) by the area that each building and its adjacent free space occupy. This is given by equations (4) and (6) for the pavilion and court cases, respectively. For the terrace form, the number of rows in the site $\left(m_{r}\right)$ is calculated by dividing whole area of site by the area that each row and its adjacent free space occupy, obtaining from equation (5).

$$
m_{b}=\frac{Z}{(x+L)^{2}}
$$




$$
\begin{gathered}
m_{r}=\frac{Z}{(x+L) y} \\
m_{b}=\frac{Z}{(y+L)^{2}}=\frac{Z}{(2 x+2 L)^{2}}
\end{gathered}
$$

Site coverage shows the percentage of total buildings footprint in the whole site area and based on the model shown in Figure 1, is obtained from equations (7), (8) and (9) for pavilion, terrace and court, respectively. Since $\mathrm{Z}$ is eliminated from the final equation, the magnitude of site area does not have any effect on the results of this analysis, hence, the results are valid for any generic site area with any dimensions as long as the layout assumptions/patters are adhered to.

$$
\begin{gathered}
C=\frac{m_{b} x^{2}}{Z}=\frac{x^{2}}{(x+L)^{2}} \\
C=\frac{m_{r}(x y)}{Z}=\frac{x}{x+L} \\
C=m_{b} \frac{2 x y+2 x L}{Z}=\frac{2 x}{(y+L)}=\frac{x}{x+L}{ }^{1}
\end{gathered}
$$

Assuming all buildings have the same number of storeys and all the storeys have the same floor area, the plot ratio of the site is obtained by multiplication of site coverage to the number of storeys showing in equations (10), (11) and (12) for pavilion, terrace and court, respectively.

$$
\begin{gathered}
P=n C=n \frac{m_{b} x^{2}}{Z}=\frac{n x^{2}}{(x+L)^{2}} \\
P=n C=n \frac{m_{r}(x y)}{Z}=\frac{n x}{x+L} \\
P=n C=n m_{b} \frac{2 x y+2 x L}{Z}=\frac{n x}{x+L}
\end{gathered}
$$

The final equation of site coverage and plot ratio for terrace and court form are the same, identifying they have similar density (all other things being equal), but have a difference in the amount of daylight received and energy performance. This latter aspect is out of the scope of this paper.

\subsubsection{Tunnel-court (Figure $1 d$ )}

The tunnel-court built form is similar to the cruciform (Martin and March, 1972) with an additional modification to Martin's model. In the original model, the roads for transportation were not clear (Steadman, 2014b). Hence, in tunnel-court model, the roads pass from the intersection of crosses and make short tunnel passages in the buildings. These so-called tunnels eliminate two storeys of buildings in their path and the distance reserved for roads is given by $d$ (road reserve). Based on Figure 1d, the number of building blocks (crosses in this case) in the site $\left(m_{b}\right)$ is calculated by dividing whole area of site by the area occupied by each cross, as follows:

$$
m_{b}=\frac{Z}{(x+L)^{2}}
$$

\footnotetext{
${ }^{1}$ Considering $\mathrm{y}=2 \mathrm{x}+\mathrm{L}$
} 
For this specific case, the site coverage for 1 and 2 storey buildings is lower than the cases with higher number of storeys as there is no coverage of the roads for 1 and 2 storey buildings. Hence there is a contribution that is subtracted from the nominator of equation (14).

$$
C=m_{b} \frac{x(x+L)+x L-2 x d[n \leq 2]^{2}}{Z}=\frac{x^{2}+2 x L-2 x d[n \leq 2]}{(x+L)^{2}}
$$

This difference is also relevant for calculating the plot ratio, since the floor area of 1 and 2 storeys are smaller than the floor area of higher storey counterparts. Assuming all buildings have the same number of storeys, the plot ratio is then obtained from equation (15).

$$
P=n C-m_{b} \frac{4 x d[n>2]}{Z}=\frac{n\left(x^{2}+2 x L-2 x d[n \leq 2]\right)-4 x d[n>2]}{(x+L)^{2}}
$$

\section{Results}

To establish the relationship between indicators and selected variables, as Excel spreadsheet tool was developed using the generated equations. It allows the opportunity of simultaneous analysis of all the influential variables. Values assigned to the variables are chosen based on the methodology and assumptions given below:

- Number of storeys changed from 1 to 40 storey.

- The storey height is considered to be $3 \mathrm{~m}$, corresponding to the normal height of storeys in residential buildings $(h=3 \mathrm{~m})$

- The distance between buildings is obtained from equation (3), and since $n$ varies from 1 to 40 , the value of $L$ is consequently changed.

- Plan depth is investigated with four different values in order to consider its influence on site coverage ( $x=6 \mathrm{~m}, x=12 \mathrm{~m}, x=18 \mathrm{~m}, x=24 \mathrm{~m}$ ).

- $\quad$ The cut-off angle is given three different values $\left(\theta=25^{\circ}, \theta=45^{\circ}, \theta=65^{\circ}\right)$

The range of plan depth choice is twofold, first to accommodate shallow to deep scenarios, and second as a means of modelling possible passive zones (light and ventilation) in the buildings. Since the minimum plan depth, in order to have passive zone, is twice the storey height (i.e. typically $6 \mathrm{~m}$ ) (Steadman et al., 2009), the value is $6 \mathrm{~m}$. For cases having windows both sides, the passive zone remains up to $12 \mathrm{~m}$. The rest of the plan depth values are chosen to be a factor of 6 in order to have idea of passive to non-passive ratio which is an applicable indicator for energy analysis of building (Ratti et al., 2005). Regarding cut-off angle, a lower bound of $25^{\circ}$ is selected in order to have longer distance between buildings and ensure sufficient solar radiation and avoid excessive over shading on the building facades. Increasing the cut-off angle allows for reduced solar radiation received by the facades, and whilst it is unlikely that $\theta$ exceeds $45^{\circ}$ in modern residential buildings (Steadman, 2014b), an angle of $65^{\circ}$ is also considered in order to identify the trends of changing indicators when buildings are very close to one another. Notably, building height, cut-off angle and plan depth are varied according to urban planning policies (themselves derived from climate, geography, culture and other factors) in different parts of the world. Hence, a comprehensive assessment over a wide range of values to cover a variety of different locations on the earth is considered. For brevity here, only results based on sample values are shown.

\footnotetext{
${ }^{2}$ Iverson bracket
} 


\subsection{Site coverage and plot ratio Vs number of storeys}

\subsubsection{Effect of number of storeys and plan depth}

Figure 2 shows the trend of site coverage and plot ratio versus number of storeys for the case of keeping cut-off angle at the constant value of $25^{\circ}$ and varying the plan depth from 6 to $24 \mathrm{~m}$ (up), and for case of having a constant plan depth of $12 \mathrm{~m}$ and varying the cut-off angle from $25^{\circ}$ to $65^{\circ}$ (down).

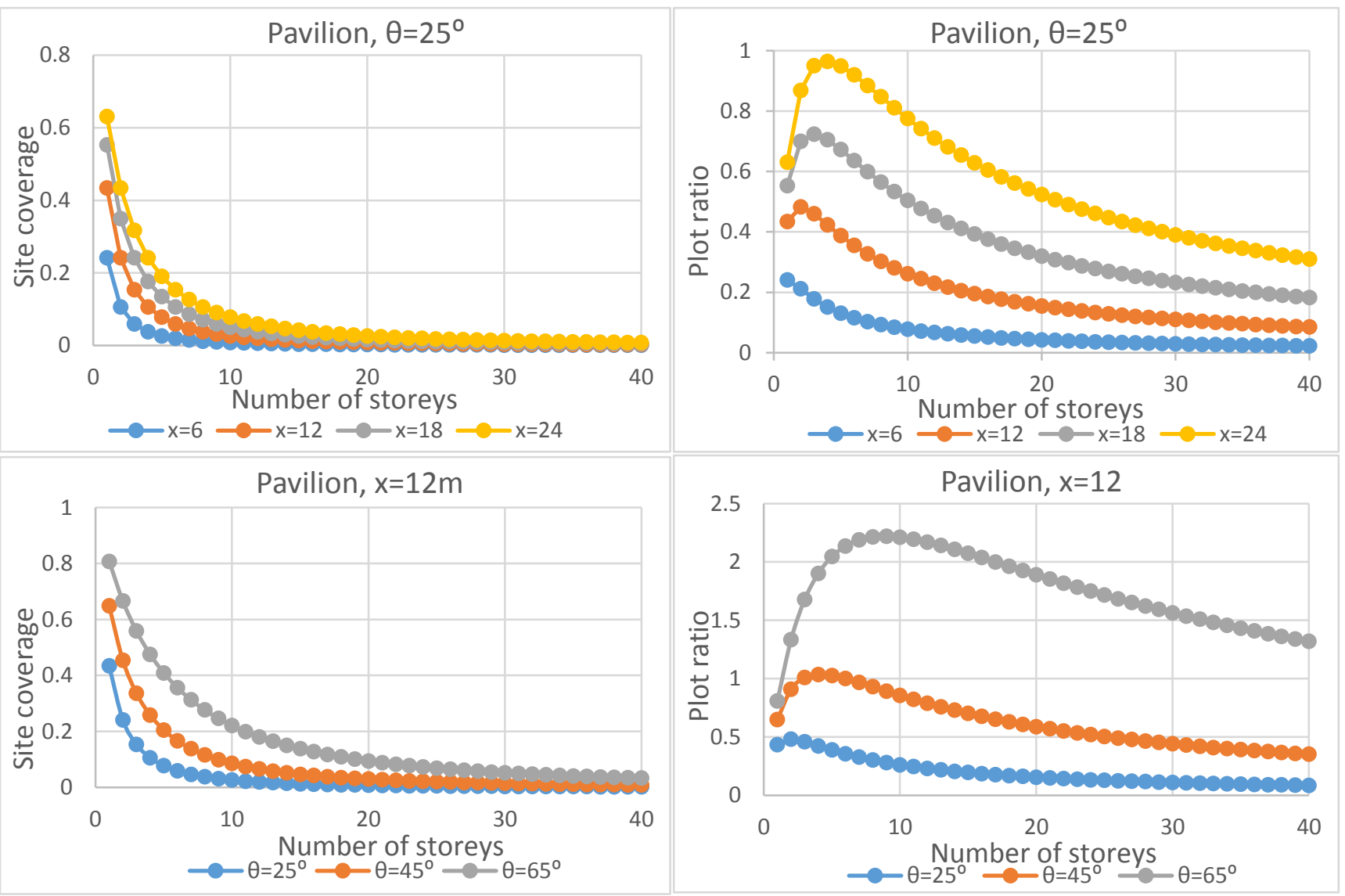

Figure 2: Trends of changing site coverage and plot ratio with increasing number of storeys for pavilion form in case of $\theta=25^{\circ}($ up $)$ in case of $x=12 \mathrm{~m}$ (down)

From Figure 2 (up) it can be seen that higher plan depths generally provide greater site coverage and plot ratio. However, a more general conclusion is that regardless of the value of plan depth, as number of storeys increases, the rate of change of site coverage and plot ratio significantly reduces and after certain number of storeys becomes tangential. Figure 2 (down) shows that higher values of cut-off angle considerably increase the site coverage of buildings, whilst substantially increasing the plot ratio of buildings (specifically, at higher number of storeys), indicating its importance as an influential parameter for these indicators. Notably, the trend curve is more acute in cases of higher cut-off angle. These conclusions are valid for all types of urban built forms considered in this study. A particular point to mention is the peak depicted on the trend line of plot ratio. This shows that there is an optimum number of storeys that gives the highest possible plot ratio for pavilion form. This is not the case for other built forms considered in the study. As it is shown in Figure 3, terrace, court and tunnel-court forms depict a continuous ascending trend in their related trend lines. The reason is that in pavilion form, as the number of storeys increase, the distance between buildings increase in four directions (toward the neighbour buildings). Crossing that certain (or optimal) number of storeys, the 
buildings locate too far from each other resulting in emergence of large open areas between buildings which leads to lower plot ratio and site coverage.

\subsubsection{Comparison of built forms}

Results for site coverage and plot ratio of mentioned built forms are now integrated in Figure 3 to facilitate a better comparison for the process.
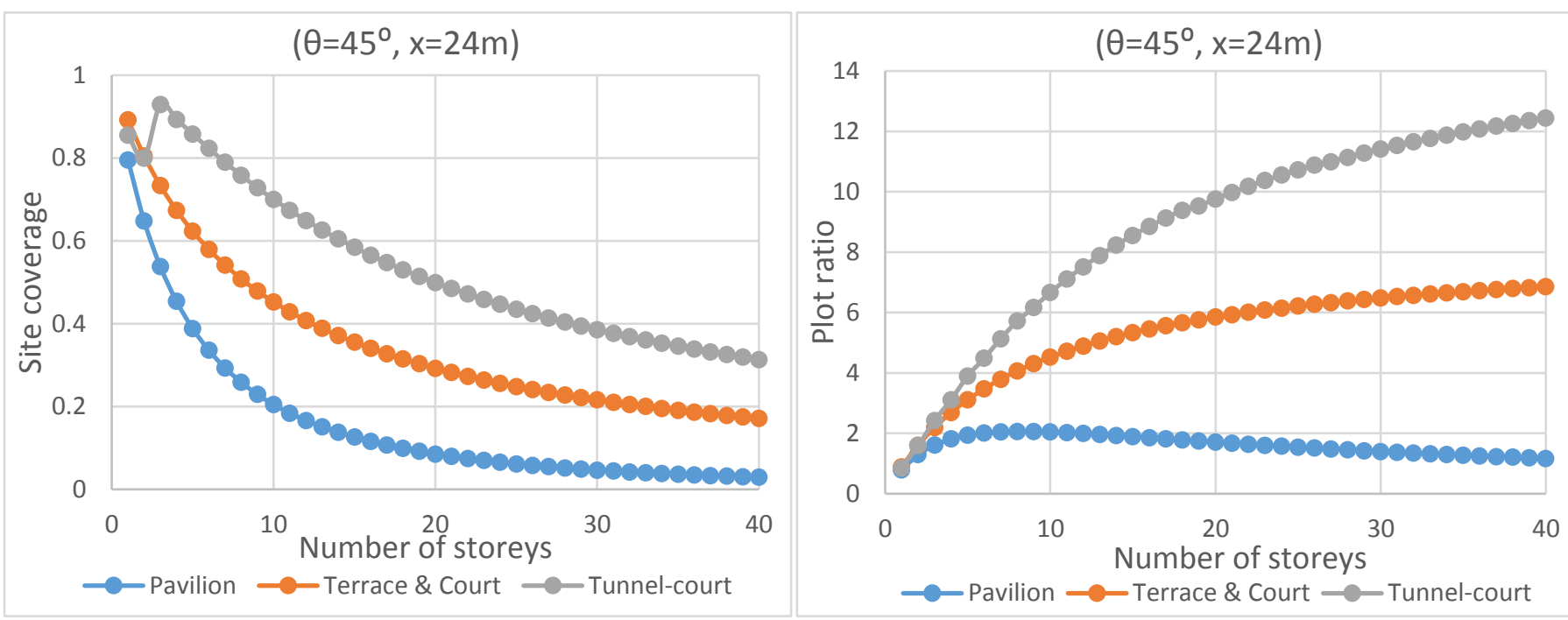

Figure 3: Comparison of site coverage and plot ratio of pavilion, terrace, court and tunnel-court forms in case of $\theta=45^{\circ}$, $x=24 m$

From the graph and for the same $x$ and $\theta$, the pavilion form always has the lowest site coverage and plot ratio regardless of number of storeys, while terrace and court forms have the same trend (Since they achieved the similar results according to equations (8) and (9) as well as (11) and (12)) but with higher values. The value of plot ratio for pavilion at its peak is around half of the terrace and court. Tunnel-court provides the greatest site coverage and its plot ratio is almost twice that of terrace and court. The peculiarity of tunnel-court form is the anomalous characteristics of the trend lines for 1 and 2 storey buildings that is due to the additional component $(2 x d,[n \leq 2])$ in equation (14), which accommodates the difference in the plan of the first two storeys as a result of the road pass from the buildings. Other values of $\theta$ and $x$ indicate the same trend.

\subsubsection{Practical cases of constant distance between adjacent buildings}

It should be emphasised that the descending trend of plot ratio after the peak in the pavilion case is due to the increase in the distance between buildings in all directions (see equation (3)) as the number of storeys increases. For the same reason, the amount of site coverage tends to zero for high-rise buildings $(n \geq 20)$. This only occurs in theory as in practical cases this rule is rarely respected, at least in horizontal direction. In different cities in the world, and based on their policies, the horizontal distance between buildings is usually kept constant and only the distance of buildings in different rows increases with respect to increasing height. For example, in hot-arid climates the distance between adjacent buildings is considered narrow (e.g. $6 \mathrm{~m}$ ) in order to benefit from shadow and shield direct sun light. In these cases, both site coverage and plot ratio of pavilion building form is much higher than the theoretical situation above. It is also the case for court form if the distance with adjacent block is kept constant. The results of this alternative assessment in the case of $L=6 \mathrm{~m}$ (in horizontal direction) are shown in Figure 4. 

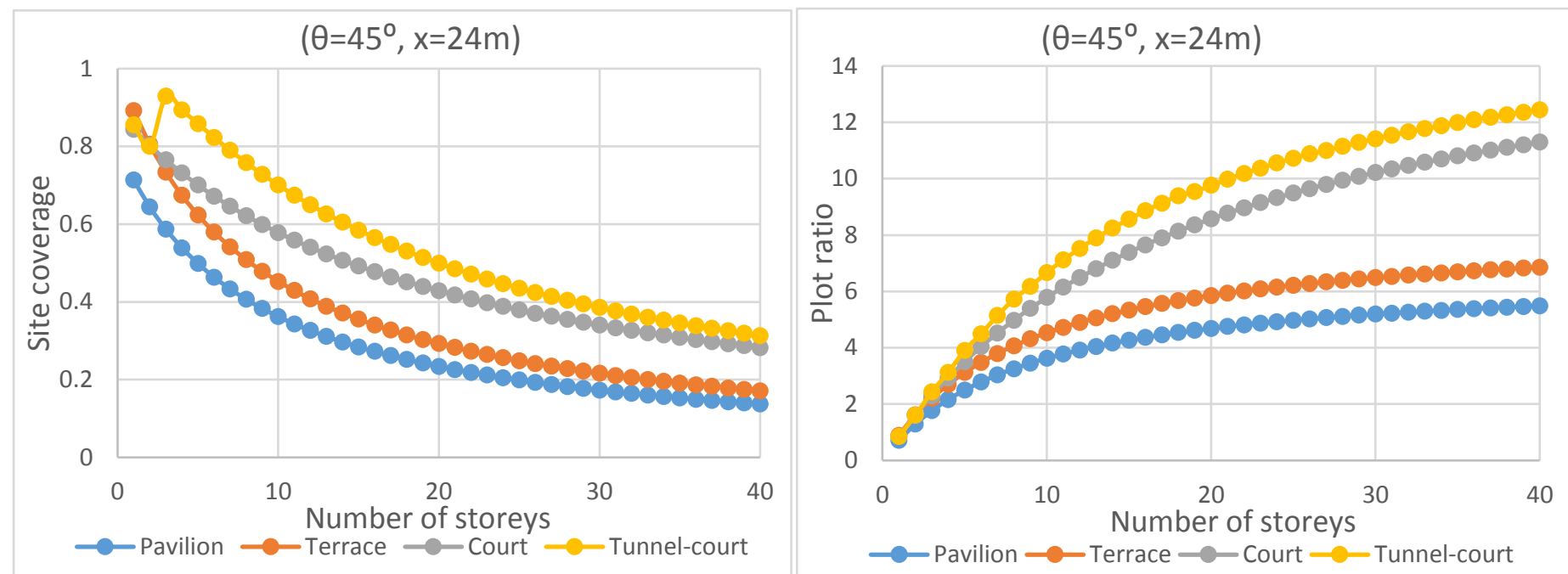

Figure 4: Comparison of site coverage and plot ratio of urban built forms in case of constant distance (6m) with adjacent buildings for $\left(\theta=25^{\circ}, x=12 \mathrm{~m}\right)$ and $\left(\theta=45^{\circ}, x=24 \mathrm{~m}\right)$

It can be seen that the pavilion form still occupies the lowest site coverage and plot ratio, whilst the difference with the terrace form is not as significant as in the previous analyses. However, in this case, court form acquires higher site coverage and plot ratio compared to the terrace form, although it has some overlap with terrace form when the number of storeys is 1 or 2 . The highest possible density can be still achieved by tunnel-court form. Moreover, there is no peak in the trend curve of pavilion and it is always ascending with $n$. Hence, the presented methodology can also be applied for different assumptions (in this case $L$ is kept constant in the horizontal direction) in order to tailor-made the results according to specific requirement.

\subsection{The Form Signature: Combining the density indicators in a single diagram}

\subsubsection{Preliminary model and its limitations}

It is of particular interest to investigate the importance of these indicators to best describing urban density. As discussed in the introduction, a set of density indicators should be employed to give a more comprehensive definition. Here, the identified indicators and parameters are combined in a single figure to depict the characteristics of any urban area with respect to landuse. Referring to the equations (10), (11) and (12), the plot ratio is obtained by multiplying site coverage and the number of storeys regardless of the form of the neighbourhood (assuming all buildings have an equal number of storeys and all the storeys have the same floor area). Using this relationship, Figure 5 shows the relative influence of these two indicators and number of storeys. It can be seen that for any value of plot ratio having a number of storeys, the corresponding value of site coverage can be obtained, and vice versa. Moreover, the distance between the lines showing the number of storeys, decreases as $n$ increases, indicating that the higher the building, the lower the rate of change of plot ratio and site coverage. This aligns to that developed by Berghauser Pont and Haupt (2007) with two main differences. First, their results were developed only for buildings up to 13 storeys, while the version presented here provides a more generic treatment, and second, their study included open space ratio (OSR) of buildings which is not included in this study since it is in opposing correlation with site coverage and can be readily calculated through basic linear formulation. 


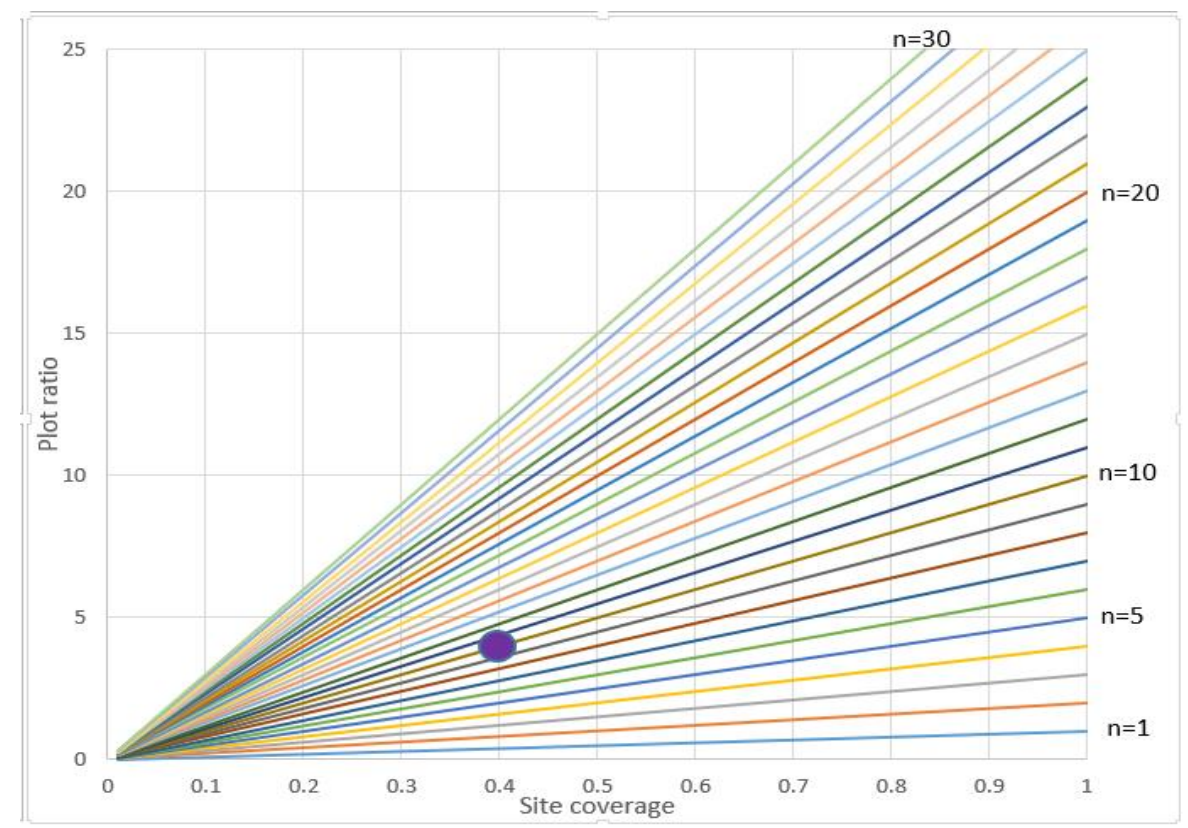

Figure 5: Relationship of plot ratio, site coverage and number of storeys with the example of the point corresponding to $P=4, C=0.4$ and $n=10$

This study is seeking the relationship of urban built form and density which are not presented in Figure 5. Hence, there remain limitations to this graph that can be addressed by introducing new parameters. Having considered a particular point on the map, it is not possible to define the type of built form corresponding to that point. It can be pavilion, terrace, court or any other built form. For instance, considering a point on the diagram corresponding to the site coverage of 0.4 , number of storeys of 10 and plot ratio of 4 (Figure 5), this could represent an urban area with any type of built form depending on the building's cut-off angle and plan depth. Some possibilities are; pavilion with $\theta=65^{\circ}$ and $x=24 \mathrm{~m}$, terrace with $\theta=45^{\circ}$ and $x=20 \mathrm{~m}$, and court with $\theta=65^{\circ}$ and $x=9 \mathrm{~m}$. Hence, the design point does not identify all characteristics of the built form.

\subsubsection{Overcoming the limitations of the characteristics in Figure 5}

To give an absolute identification to all the points on the graph, the influence of plan depth $(x)$ and cut-off angle $(\theta)$ should also be included. Therefore, combining the effect of these two geometrical parameters introduces what is now termed the Form Signature on the plot that distinguishes each urban built form considered in this study. Since plan depth and cut-off angle are independent variables, the range of both cannot be shown on a single diagram simultaneously. As a result, a suite of guidelines are obtained for urban planners which are an extension of what is shown in Figure 5. Steadman (2014b) compared cut-off angle and plan depth of different built forms using specific values as an example.

\subsubsection{Pavilion, Terrace and Court}

To determine the effect of plan depth, the value of cut-off angle is fixed on a certain number and the assessment is done for different values of plan depth ( $x: 6$ to 30). Then, this assessment is repeated for different values of $\theta$. Corresponding diagrams for cut-off angle values of $25^{\circ}$, $45^{\circ}$ and $65^{\circ}$ are illustrated in Figure 6 . Since the plot ratio and site coverage of terrace and court form are similar, the diagrams showing their land-use behaviour are the same. 

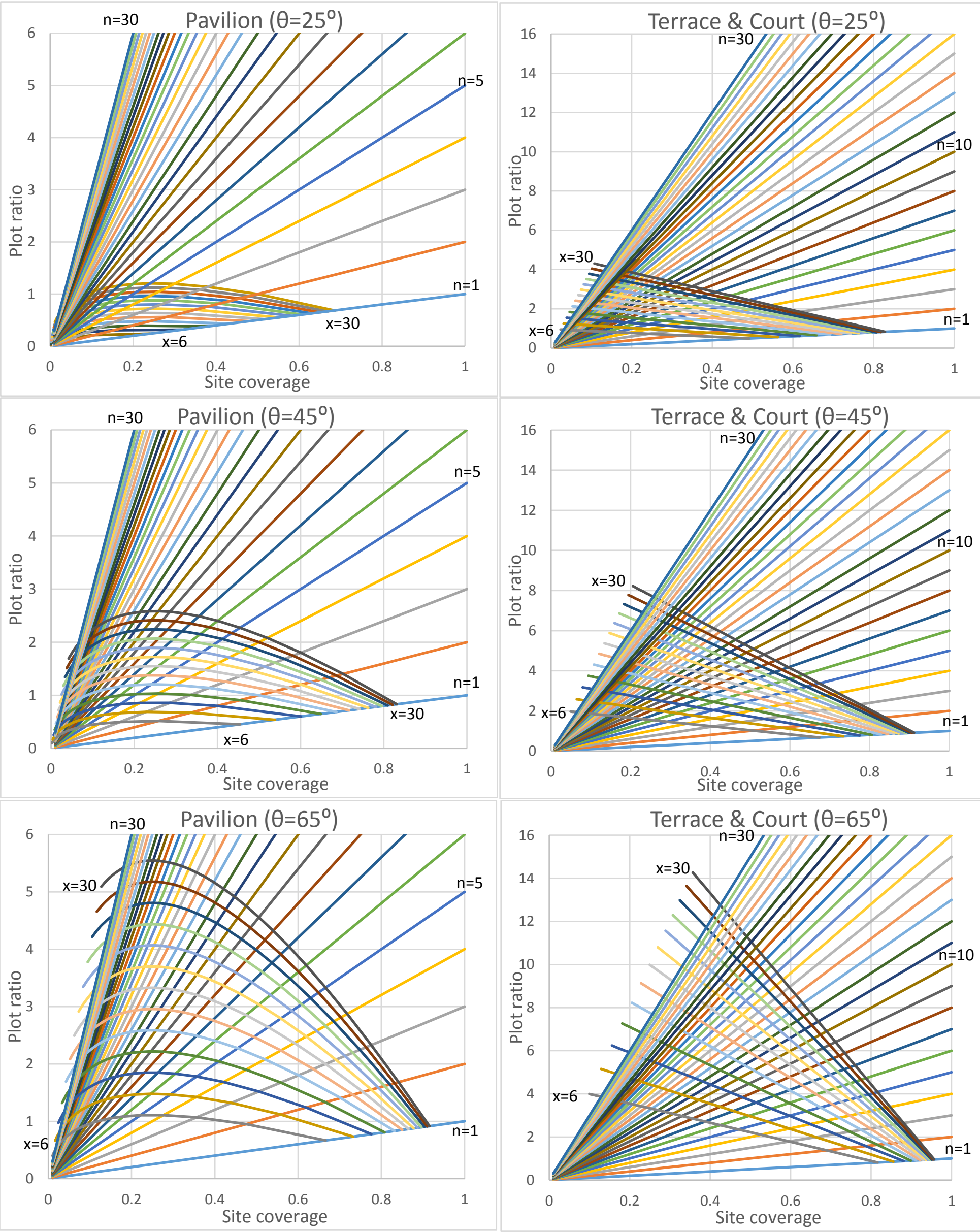
Using this set of characteristics, the density of any pavilion or terrace/court form neighbourhood with plan depths in the range $6 \mathrm{~m}$ to $30 \mathrm{~m}$ (or higher if required, via replotting) with three cut-off angles of $25^{\circ}, 45^{\circ}$ or $65^{\circ}$, can immediately be identified as a unique point in either of the composite diagrams. Indeed, any district with these forms can be identified with a unique point on either of those diagrams. To accommodate values not shown in the diagrams, interpolation or extrapolation can be used.

\subsubsection{Tunnel-court}

This newly developed built form is substantially different to more traditional popular forms, and consequently alters the assumptions that are classically made. In tunnel-court form, although the number of storeys is assumed to be equal, the floor area of all storeys are not, since the $1^{\text {st }}$ and $2^{\text {nd }}$ storeys of buildings are smaller in floor area as the roads pass through them. Hence, the plot ratio is not simply the multiplication of site coverage to the number of storeys but is obtained from equation (15). Having undertaken corresponding studies for tunnel-court forms, the land-use characteristics of it are shown in Figure 7. 


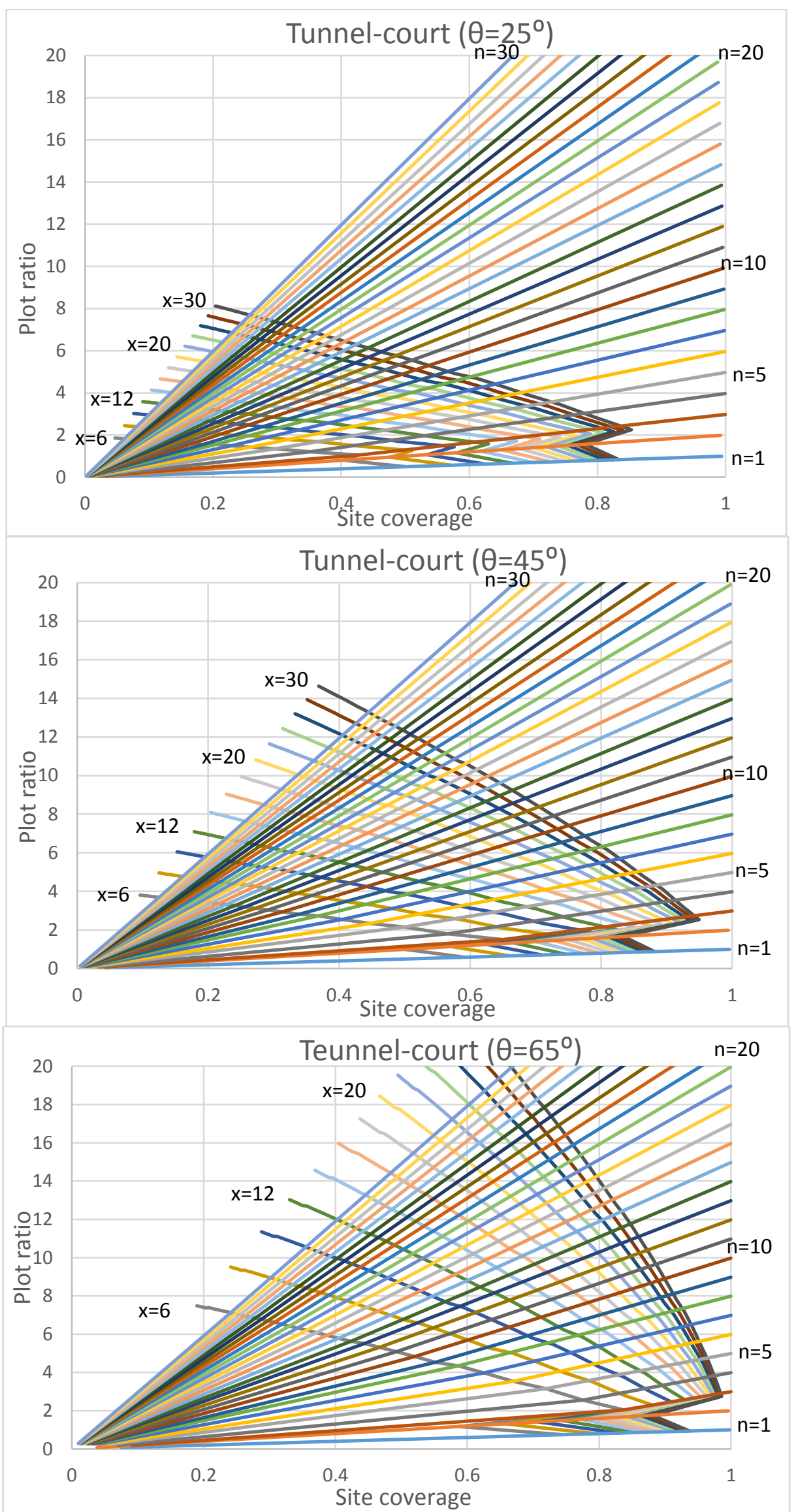

Figure 7: Plot ratio, site coverage, number of storeys and plan depth for tunnel-court form in case of cut-off angle of $25^{\circ}$, $45^{\circ}$ and $65^{\circ}$ 
The anomalous behaviour of the lines (showing trend of $x$ ) at the starting point is due to the different floor area of $1^{\text {st }}$ and $2^{\text {nd }}$ storeys.

Presenting the results of this study is in analogy with LT method (Baker and Steemers, 2003). It proposes set of graphs (handbook) that the appropriate one can be chosen according to the initial conditions. It is also available as Excel spreadsheet tool with the potential of being enhanced to online tool or software in the future.

\section{Discussion}

The Form Signature tool, illustrated as a suite of graphs, could satisfy the knowledge gap for systemically relating urban built form with urban density. It not only excludes the effect of 'interfering' factors from the analysis, but also shows the simultaneous relationship of all pertinent variables in the form-density equations. There are two main applications for this tool that are discussed in following sections.

\subsection{Application to planning regulation for new district development}

In general, the diagrams shown in Figure 6 and Figure 7 are the intersection of five key parameters that influence the density of a built area, and knowledge of one parameter a-priori enables the others to be chosen on the basis of relative compromise. Knowing four of the parameters, the remaining parameter can be readily obtained and the precise design of a master plan achieved. An important application of these graphical guidelines is setting threshold for variables, specifically the density indicators. Since "development control is an integral component of urban land use policy" (Tang and Tang, 1999), this has been shown to be very beneficial for controlling and monitoring urban development by urban planners and policy makers. They normally restrict parameters such as plot ratio or the height of urban developments (Lai and Ho, 2001) in order to optimize the contexts such as urban resilience (Sharifi, 2019), energy (Moghadam et al., 2019), population to land ratio and transportation as sustainability dimensions of the urban built environment (Deng et al., 2019). Indeed, it can visually show that by changing one parameter, how the value of others changes correspondingly.

In the sequence, a number of real cases are used to demonstrate the efficacy of the presented results:

- From regulations in the city of Tokyo, the maximum plot ratio of 1 and site coverage of 0.5 is set for category II of low-rise residential zone, as restrictions (Plaza Homes, 2017). Considering pavilion form and cut-off angle of $45^{\circ}$ to achieve acceptable daylight availability while satisfying efficient use of limited lands in the city, the admissible box for planning is shown in Figure 8 (left). The graph clearly shows that maximum allowable plan depth is $12 \mathrm{~m}$ as a consequence of primary planning regulations. Hence, combining the plan depth and number of storeys inside the box, the optimum design point can be obtained.

- A guide for controlling residential development in Singapore established the maximum plot ratio of 2.8 for high density development with an equivalent number of storeys of 36 (StackedHomes, 2018). According to Figure 5, it needs to occupy site coverage of less than 0.1 to achieve this goal.

- A high density built environment in the city of Nablus has a plot ratio of 1.29 and site coverage of 0.6 (Coccolo et al., 2016). According to Figure 5, the average number of storeys would be around 2 .

- Tang and Tang (1999) discussed the maximum plot ratio of 6 for domestic buildings in Hong Kong. It means different combinations of site coverage and building storeys can be chosen to achieve this plot ratio restriction. E.g. from a decision to commit to 10 - 
storey buildings, the maximum allowable site coverage will be 0.6 (based on the Figure 5) since the limit of 6 is already fixed for plot ratio.

In all the above cases, if the built form is known planners can immediately check the related set of guidelines and choose the best match of plan depth and cut-off angle for their plan from Figure 6 and Figure 7. For instance, in a hot-arid climate, the court form acquires many advantages (Javanroodi et al., 2018), and hence, the rightmost column of Figure 6 should be considered. Then, if policy means constructing the area with a plot ratio of 4 , number of storeys of 7 and cut-off angle of $45^{\circ}$, looking at the related diagram, the site coverage must be 0.57 and the buildings must possess a plan depth of $27 \mathrm{~m}$ (

Figure 8). Alternatively, if there is a limitation on cut-off angle and plan depth, the most suitable urban built form can be chosen.
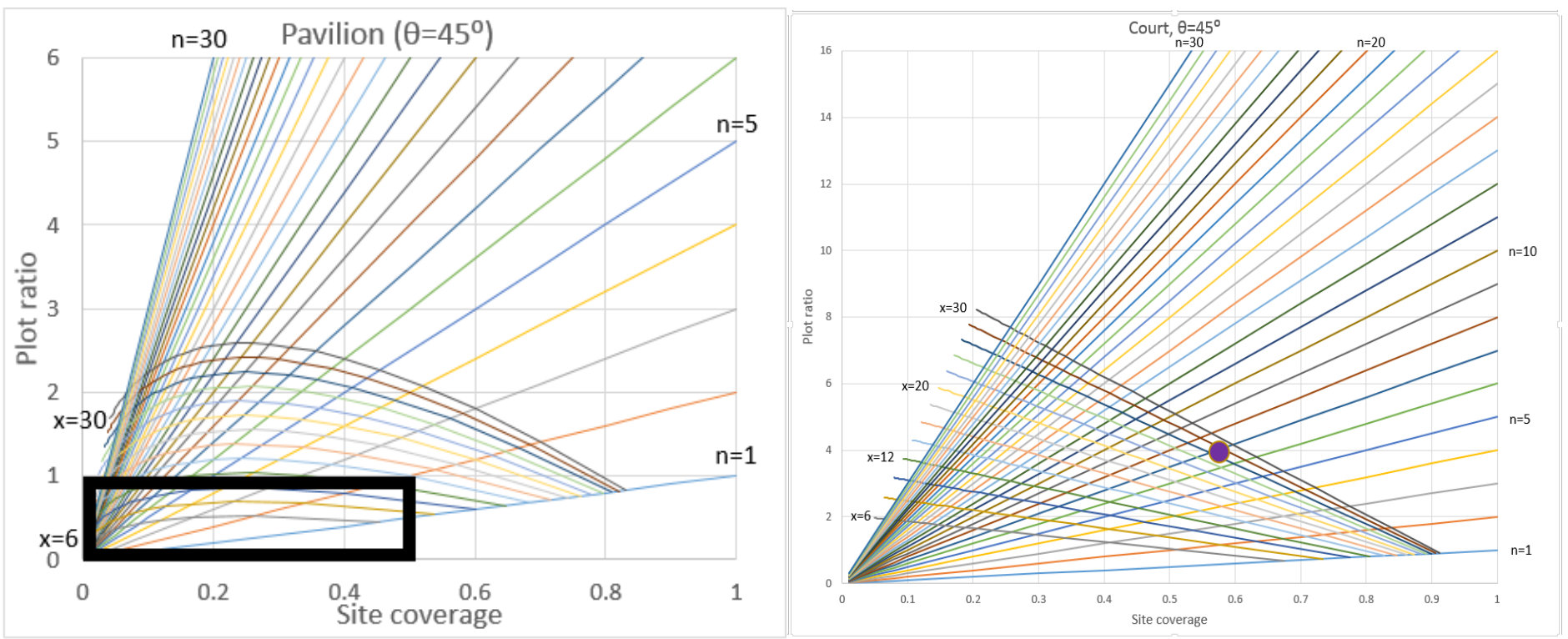

Figure 8: The planning restrictions in Tokyo showing the admissible box (left), Example of design point for $P=4, n=7$, $\theta=45^{\circ}, C=0.57$ and $x=27 \mathrm{~m}$ (right)

\subsection{Application to real existed cities}

\subsubsection{Urban built form, density and climate}

Built forms considered in this study currently exist in different cities around the world. It is important to recognize the characteristics of built forms that have emerged for different climatic conditions using the results of this study to build their respective maps which show their Form Signature. To this end, 32 districts from 19 cities have been selected as case studies to define their land-use characteristics using the graphical guidelines. The site coverage and plot ratio of the case studies are calculated using their plan depth and number of storeys. This information, plus the climatic condition of the cities based on the Koppen climate classification (Rubel and Kottek, 2010), is detailed in Table 1. 


\begin{tabular}{|c|c|c|c|c|c|c|}
\hline Built Form & City (District) & $\mathbf{x}$ & $\mathbf{C}$ & $\mathbf{n}$ & $\mathbf{P}$ & Climate \\
\hline \multirow{12}{*}{ a) Pavilion } & Auckland (Ormiston) & 13 & 0.26 & 2 & 0.53 & Temperate $(\mathrm{Cfb})$ \\
\hline & Melbourne (Oakleigh East) & 12 & 0.34 & 1 & 0.34 & Temperate $(\mathrm{Cfb})$ \\
\hline & Barcelona (Ramble de Guipuscoa) & 20 & 0.23 & 15 & 3.48 & Temperate (Csa) \\
\hline & Rome (Municipio V) & 15 & 0.32 & 5 & 1.62 & Temperate (Csa) \\
\hline & Tehran (Parand) & 24 & 0.35 & 6 & 2.1 & Temperate (Csa) \\
\hline & Putrajaya (Taman Pinggiran Putra) & 15 & 0.39 & 1 & 0.39 & Tropical (Af) \\
\hline & Las Palmas (Calle Virgen del Pilar) & 26 & 0.22 & 13 & 2.84 & Dry $(\mathrm{Bwh})$ \\
\hline & Singapore (Bukit Timah) & 12 & 0.23 & 2 & 0.46 & Tropical (Af) \\
\hline & Singapore (Bukit Panjang) & 42 & 0.17 & 28 & 4.76 & Tropical (Af) \\
\hline & Hong Kong (Central) & 40 & 0.26 & 42 & 10.71 & Temperate (cfa) \\
\hline & Boston (Winter Hill) & 11 & 0.37 & 3 & 1.11 & Continental (Dfa) \\
\hline & Sao Paolo (Jardim Sao Saverio) & 20 & 0.17 & 18 & 3 & Temperate (Cfa) \\
\hline \multirow{10}{*}{ b) Terrace } & London (Hither Green) & 8 & 0.21 & 2 & 0.42 & Temperate $(\mathrm{Cfb})$ \\
\hline & Lincoln (Monks Road) & 11 & 0.45 & 2 & 0.9 & Temperate $(\mathrm{Cfb})$ \\
\hline & Prague (Solidarita) & 15 & 0.3 & 2 & 0.6 & Temperate $(\mathrm{Cfb})$ \\
\hline & Barcelona (La Verneda I la pau) & 15 & 0.38 & 12 & 4.6 & Temperate (Csa) \\
\hline & Oslo (Sofienberg) & 12 & 0.29 & 5 & 1.46 & Continental (Dfb) \\
\hline & Tehran (Parand) & 14 & 0.4 & 3 & 1.2 & Temperate (Csa) \\
\hline & Putrajaya (Taman Pinggiran Putra) & 18 & 0.57 & 2 & 1.14 & Tropical (Af) \\
\hline & Las Palmas (Calle Henry Dunant) & 8 & 0.33 & 4 & 1.32 & Dry (Bwh) \\
\hline & Singapore (Ghim Moh Road) & 16 & 0.22 & 14 & 3.08 & Tropical (Af) \\
\hline & Boston (Black Bay) & 16 & 0.31 & 5 & 1.56 & Continental (Dfa) \\
\hline \multirow{8}{*}{ c) Court } & Barcelona (Lesquerra de Leixample) & 25 & 0.52 & 6 & 3.13 & Temperate (Csa) \\
\hline & Prague (Vinohrady) & 17 & 0.42 & 5 & 2.1 & Temperate $(\mathrm{Cfb})$ \\
\hline & Vienna (Johannesgasse) & 16 & 0.43 & 5 & 2.13 & Temperate $(\mathrm{Cfb})$ \\
\hline & Rome (Municipio V) & 12 & 0.39 & 8 & 3.15 & Temperate (Csa) \\
\hline & Oslo (Sverdrups Gate) & 15 & 0.48 & 4 & 1.93 & Continental (Dfb) \\
\hline & Casablanca (Alvalfeh) & 14 & 0.45 & 6 & 2.57 & Temperate (Csa) \\
\hline & Muscat (Al Ghubrah South) & 6 & 0.33 & 6 & 2 & Temperate (Csb) \\
\hline & Santiago (Villa Los Peumos) & 7 & 0.26 & 3 & 0.78 & Temperate $(\mathrm{Csb})$ \\
\hline \multirow{2}{*}{ d) Tunnel-court } & Casablanca (Casbat Amin) & 9 & 0.85 & 6 & 5.12 & Temperate (Csa) \\
\hline & Vienna (Hofmusikkapelle) & 20 & 0.8 & 5 & 4.02 & Temperate (Csa) \\
\hline
\end{tabular}


Figure 9 shows the aerial photos of the selected districts from examined cities.

a)

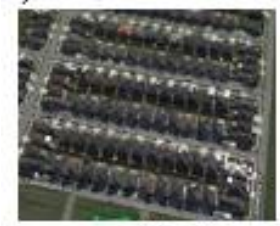

Auckland

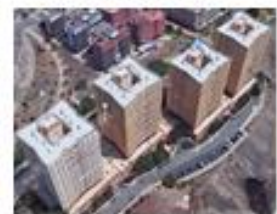

Las Palmas

b)

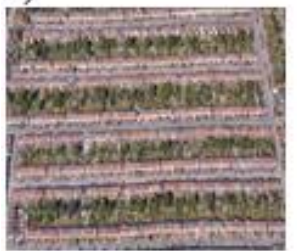

London

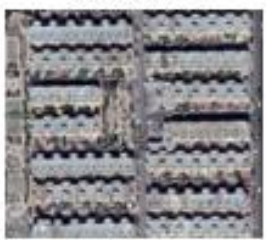

Tehran

c)

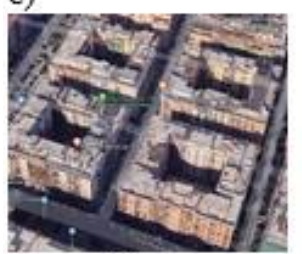

Rome

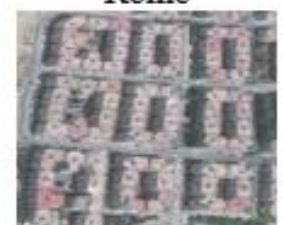

d)

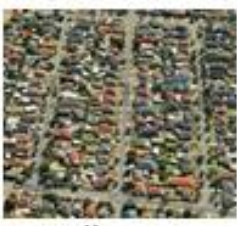

Melbourne

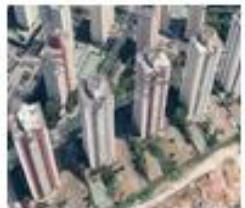

Sao Paolo

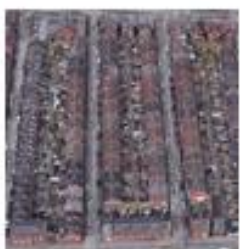

Lincoln

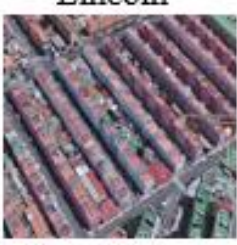

Las Palmas

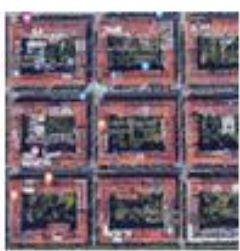

Prague

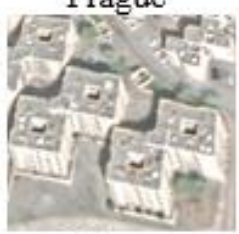

Muscat

Vienna

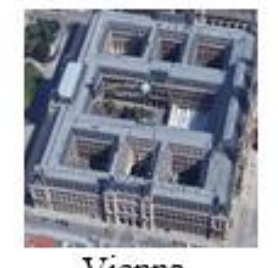

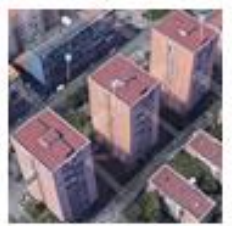

Barcelona

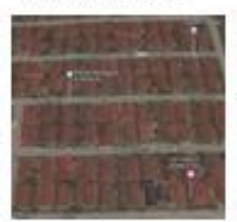

Putrajaya

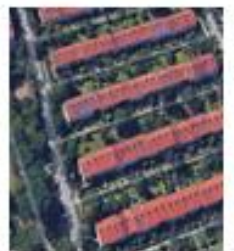

Prague

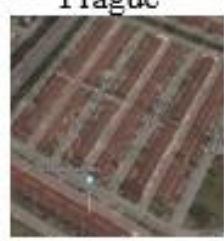

Putrajaya

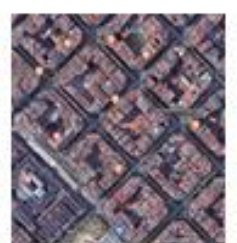

Barcelona

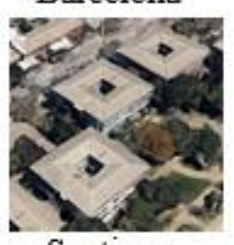

Santiago

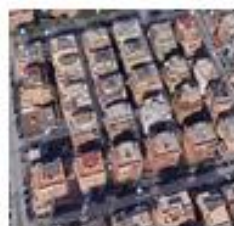

Rome

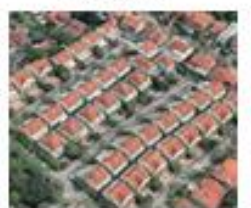

Singapore

(low-rise)

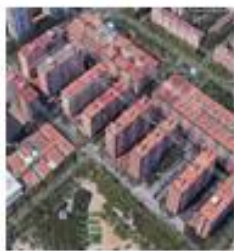

Barcelona

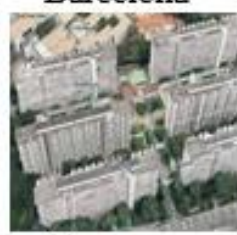

Singapore

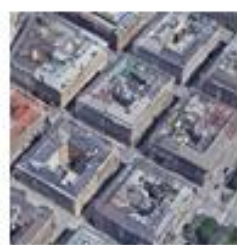

Vienna

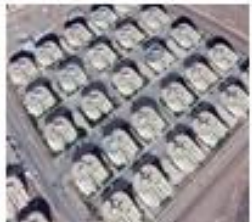

Tehran

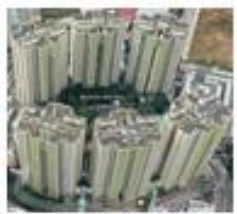

Singapore

(high-rise)

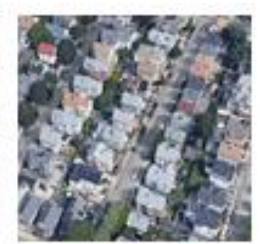

Boston

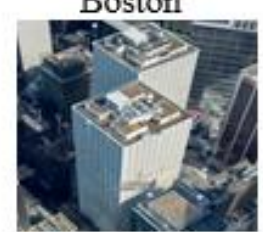

Hong Kong

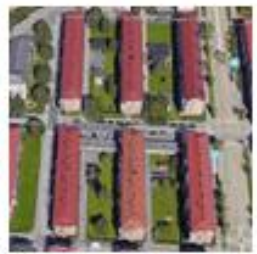

Oslo

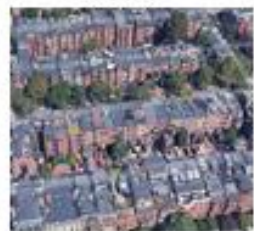

Boston

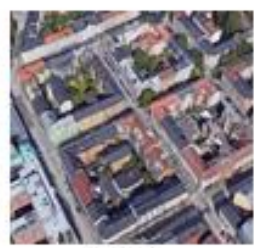

Oslo

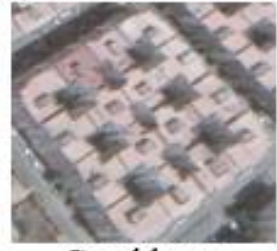

Casablanca

Figure 9: Picture of the area of the cities considered as case study a) Pavilion b) Terrace c) Court d) Tunnel-court 

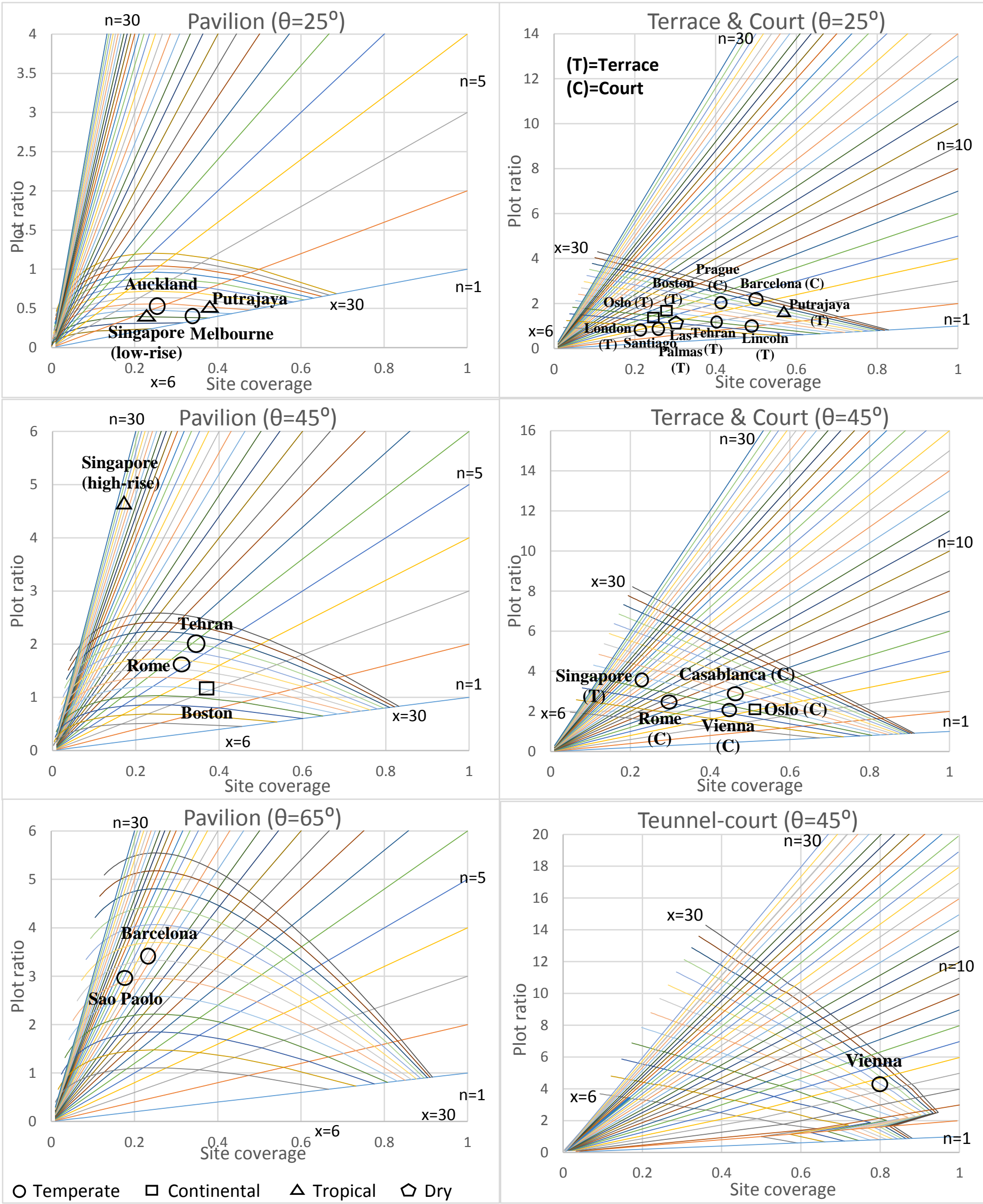

O Temperate $\square$ Continental $\Delta$ Tropical $\square$ Dry

Figure 10: Demonstration of the case studies on the graphical guidelines as it shows their " Form Signature" 
Figure 10 illustrates the Form Signature of the areas considered in the case studies. It can be seen that there is one point on the graphs which indicates the unique characteristics of the district i.e. any ambiguity resulting from consideration of different built forms is removed. The graphs relating to $\theta=25^{\circ}, 45^{\circ}$ and $65^{\circ}$ are shown as exemplars, although others can readily be generated. For similar reasons, in a few cases, the cities are only approximately attributed on the graphs for illustrative purposes. Cases of Las Palmas and Hong Kong (pavilion), Prague and Barcelona (terrace) and Casablanca (tunnel-court) are not shown since their cut-off angles are about $52^{\circ}, 75^{\circ}, 18^{\circ}, 50^{\circ}$ and $80^{\circ}$, respectively.

Although districts would have ideally been selected with consistent form and shape, in reality many built districts do not have same number of storeys, cut-off angle and plan depth over all their area. In many cases, deformed growth of cities has also been observed, and a mixture of different built forms can be seen in some areas. One of the interesting functions of the presented results is defining the average cut-off angle of the cases considered since an exclusive cut-off angle can be obtained from the graphs that can be considered as an identity for the district. This is a very important finding as cut-off angle has a direct relationship with daylight availability of buildings that is an influential parameter for energy analysis of buildings on an urban scale. The case of non-uniform distribution of buildings in site (density gradient not equal to one), can be justified by change in the values of cut-off angle in Form Signature tool.

By the way of comparison between terrace and court forms, for instance, it can be concluded that areas with court form generally acquire a higher cut-off angle compared to terrace form. The case of tunnel court in Vienna demonstrates the highest site coverage among other case studies that is a validation for the results presented in section 3.1.2.

To establish a possible relationship between climatic condition of the cities and their form and density, the cities were classified on the graphs based on their climate. It can be concluded that there is no clear relationship between climate zones and the form and density of the built areas that can be recognized, or at least it is not a substantial effective factor for contemporary buildings. In certain climate zone, it is seen that climate, as a factor to shape built form, is the secondary to cultural aspects. For example, the court form is a very popular form in European cities, nevertheless, in the cities with similar climate and latitude in the US or Asia, they can rarely be found. There can also be overriding reasons that a special type of climate does/doesn't use a specific built form, such as population, available land and family wealth, which needs further analysis in the future. Furthermore, since this classification is based on the main groups of climates defined by Koppen, it is a general climate analysis and there are many subgroups that may have specific influence on form and density.

\subsubsection{Urban built form, density and energy}

Connecting the results of this study with heat map of the cities (an example is shown in Figure 11) is another important application of these guidelines. Distinguishing the hot spots on the heat map and finding their corresponding points on the Form Signature diagrams, the planners can identify the worst/best form and density in urban areas. It helps the future urban policies to be more precise regarding the energy efficiency of growing urban areas.

Figure 11 (up) shows the heat map of city of Lincoln in UK and its two areas with high (1) and low (2) heat intensities. In Figure 11 (down), the area 1 with high heat density is shown in the left side with site coverage of 0.45 , plot ratio of 0.9 and cut-off angle of $25^{\circ}$, while the area 2 with low heat intensity with lower cut-off angle $\left(15^{\circ}\right)$, site coverage $(0.25)$ and plot ratio $(0.5)$, representing a lower density, is shown in right side. By defining the statistical data of heat consumption of whole city on the Form Signature diagrams, the relationship of form, density and energy demand of city can be established. 

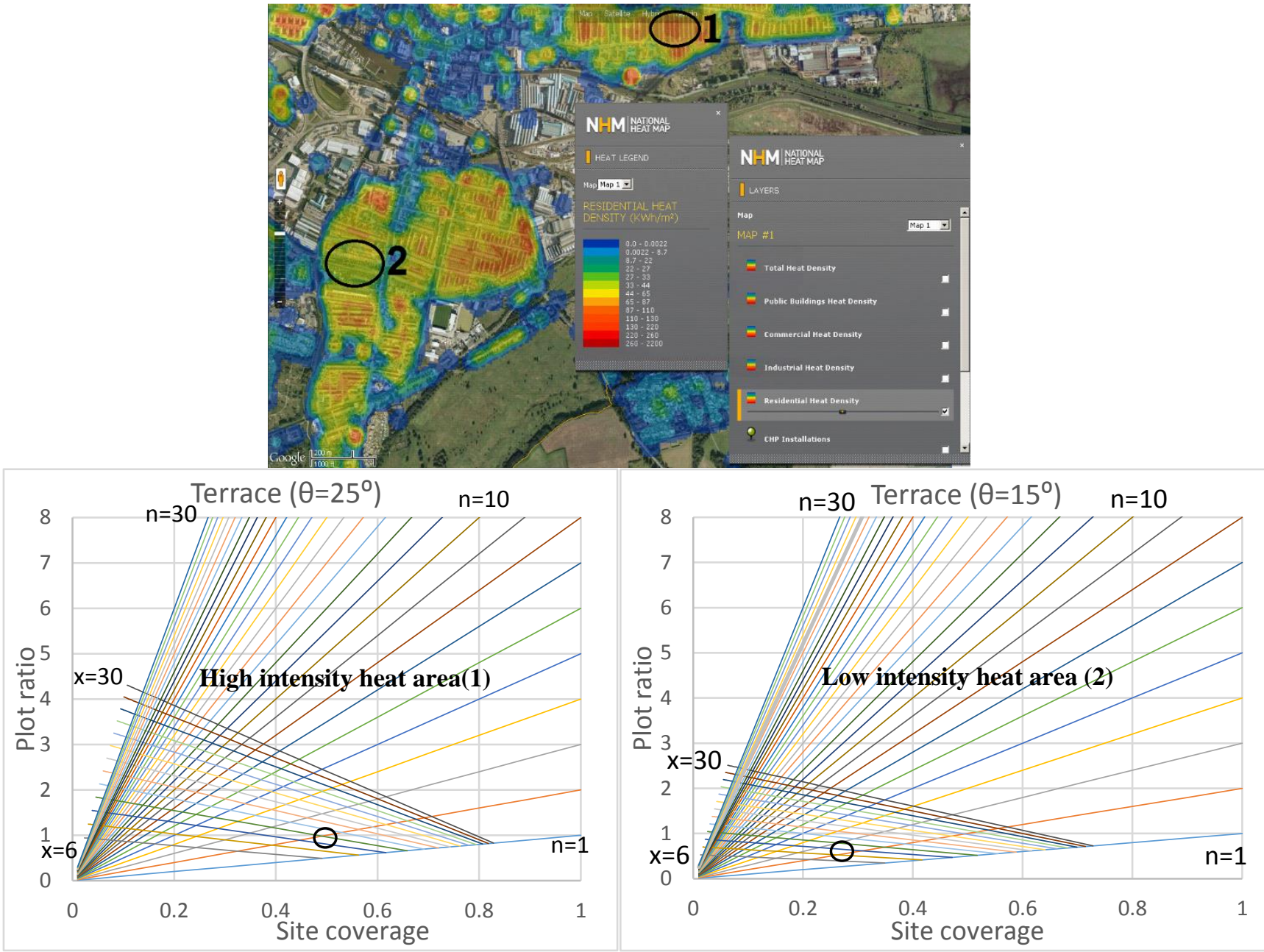

Figure 11: Heat map of heat energy consumption in the city of Lincoln (up), corresponding points on Form Signature diagrams: high intensity heat (down-left), low intensity heat (down-right)

\subsubsection{Urban built form, density and society}

McHarg (1969) assessed the propagation of several social issues including physical and mental diseases in the city of Philadelphia from statistical data. The outcomes were illustrated on maps of the city as shown in the Figure 13. 


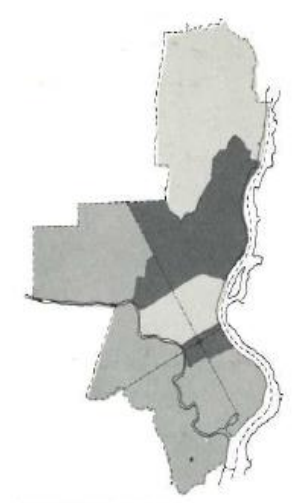

HEART DISEASE

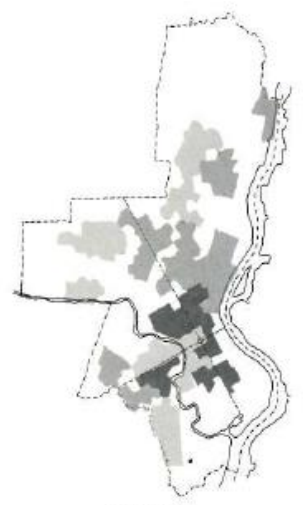

SUICIDE

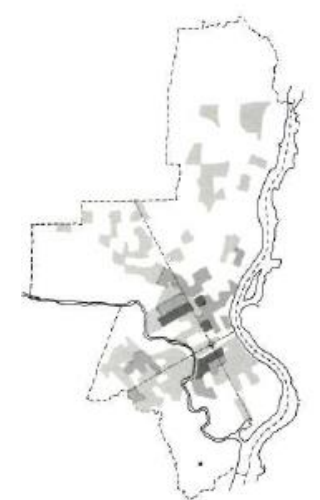

DRUG ADDICTION

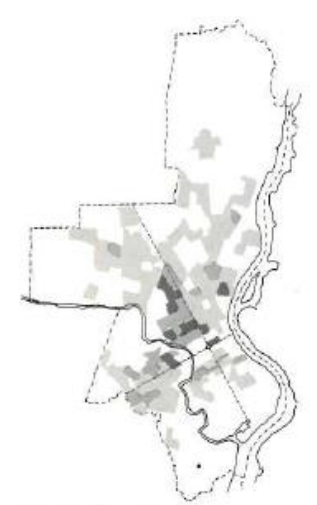

ALCOHOLISM

Figure 12: Social issues map of Philadelphia. Adopted from book of Design with Nature (McHarg, 1969)

Similarly, the crime map of the city of Lincoln published by Lincolnshire Police (2019), is shown in Figure 13.

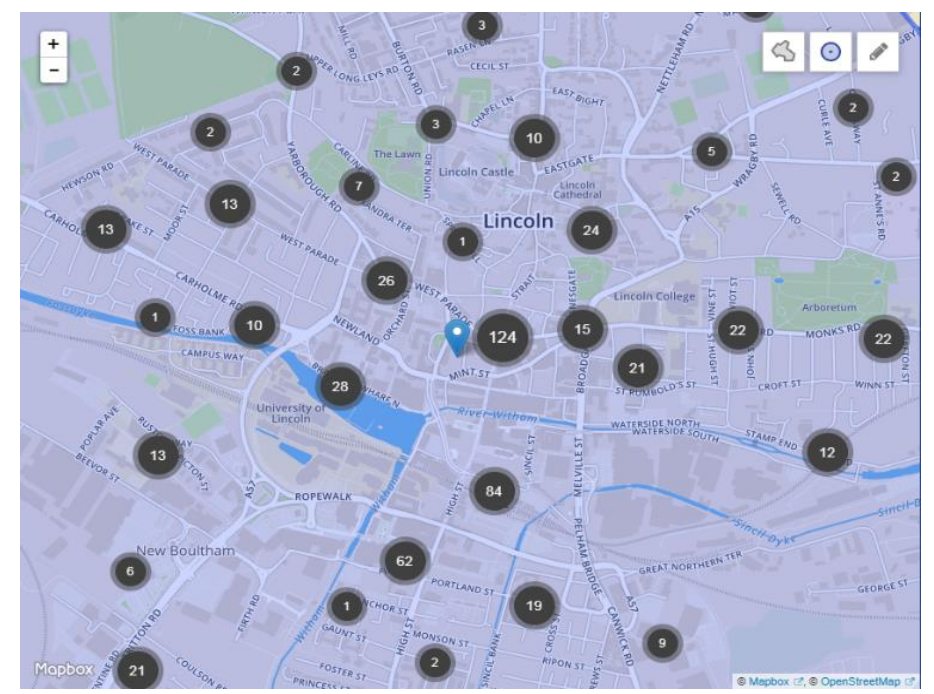

Figure 13: Crime map of Lincoln. Adopted from (Lincolnshire Police, 2019)

Coinciding the geography of diseases, suicide or crimes with Form Signature diagrams, the best urban form and density to achieve more socially sustainable city can be identified. The spots of the diagram with low intensity of those problems are the favourite urban form and density that are recommended to be considered in future policies.

In addition, the Form Signature proposed here, postulates the interconnection of urban form and density with socio-economic variables or geometrical parameters such as passive zone floor area. This enables us to achieve more accurate plans for greater degrees of economic and energy sustainability.

However, these are examples of the applications of the Form Signature tool in urban planning that needs precise statistical analysis which is out of the scope of this paper. The case studies were used to validate this model. Built form of traditional cities emerged from millennium of bottom-up decision-making process. In other word, from morphological perspectives, traditional urban built forms emerge consistently through the application of many local interconnected design decisions that shape the overall, global, city plan. The proposed Form Signature is designed to accommodate both formal (orthodox) and informal (traditional) urban forms. 


\subsection{Implications for policy}

In general, urban planning policies are defined based on a variety of factors including available land, property market forces, financial restrictions, social needs and efficient energy consumption patterns. The development and growth of cities needs to broach the three subsets of sustainability: social, economic and environmental. The Form Signature tool enables planners and policy makers to achieve sustainability objectives by identifying the most suitable urban form/density permutations.

Finally, by overlaying different variables of sustainability on the Form Signature, the diagrams propose resilient solutions for future urban developments (Figure 14). The common area of all analysed components on the diagram demonstrates the optimum urban form and density of the city in relation to its social, economic and climatic condition. This tool can be used to shape urban planning policies in the future. In other words, The Form Signature tool enables us to transform urban morphology to urban policy.

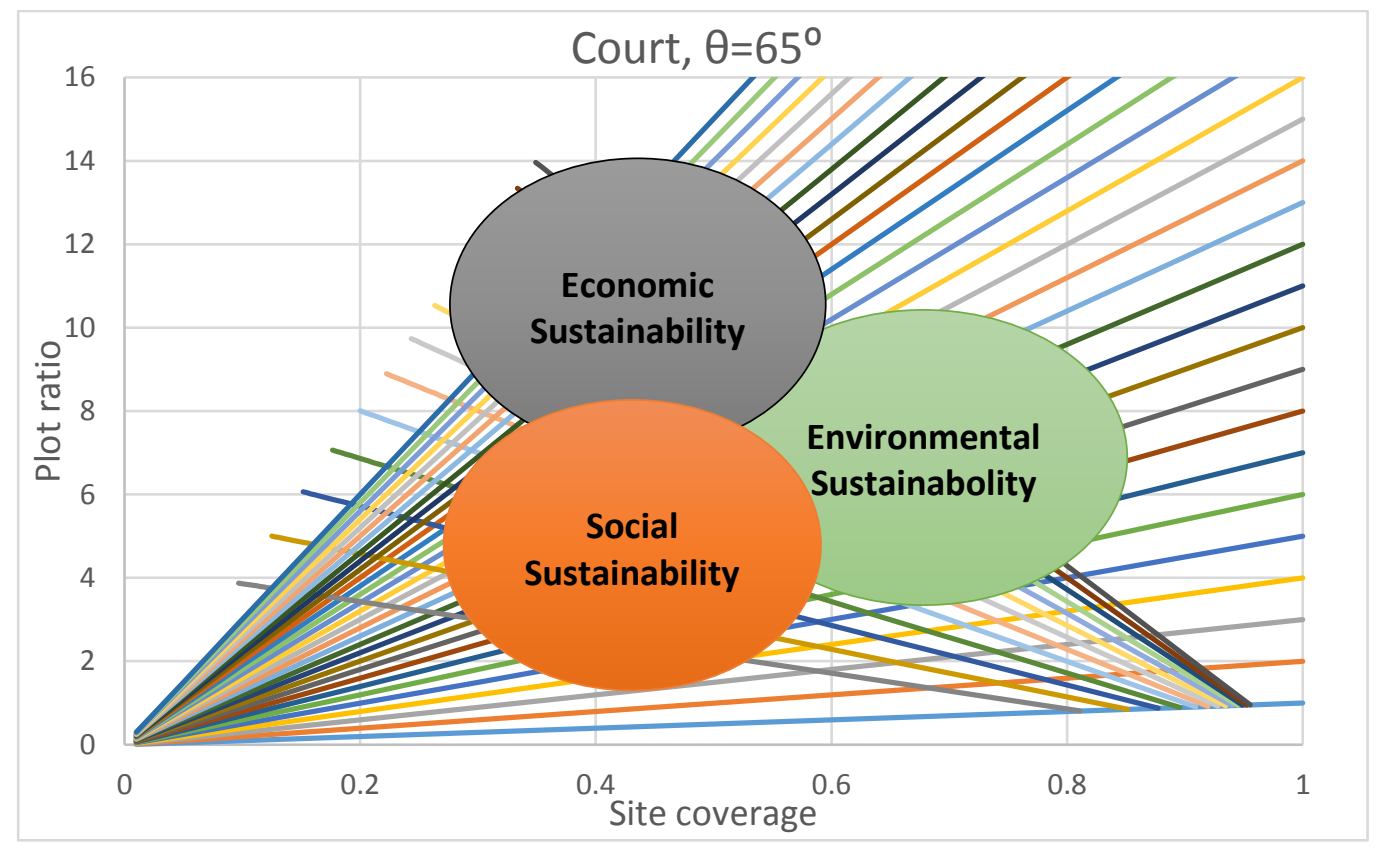

Figure 14: Coinciding the sustainability components on Form Signature diagrams

\section{Conclusion and future work}

As mentioned in the introduction, the world is facing the challenge of enormous urban development. The findings reported in this paper suggest rational ways of growing cities globally that enables the best possible design conditions for new cities. A set of guidelines providing a graphical means of qualitatively identifying inter-parameter sensitivity of four built forms has been presented through the introduction of Form Signature. The presented results facilitate identification of optimum planning conditions for sustainable development of future cities.

The guidelines recognise that there is no globally accepted definition of optimum absolute density as it is highly dependent on the consideration of different aspects that are determined by urban policies. For instance, the most appropriate urban form and density in the case of targeting lowest energy consumption is different from the case of targeting the highest economic benefits or social sustainability.

Results of case study analyses show that 1) there is no significant trend between climate and built form/density of urban areas. 2) Areas with court form have been built with higher cut-off angle compare to areas with terrace form. 
In general, building higher does not directly mean higher density as it usually increases plot ratio (except in the case of pavilion) and decreased site coverage. Hence, it is dependent on the desired characteristic of the built area. Also, after exceeding a certain number of storeys, for each of the built forms, no significant influence on density indicators is evident. The higher the cut-off angle, the sharper the slop of the lines showing plan depth. In this case, the $x$ lines sweep larger areas of the graphs meaning that higher plot ratio and site coverage can be achieved. Furthermore, the paper introduces a new type of urban form, termed tunnel-court, which is able to achieve the highest density among the others considered in this analysis. For the same site coverage, tunnel-court always achieves higher plot ratio while pavilion exhibits lowest plot ratio.

Development of the Form Signature concept establishes a basis for a form design tool (handbook), and due to the generic nature of the proposed tool, they can be more readily utilized by practitioners, urban planners, policy makers, engineers and architects in order to develop the most appropriate built form and density in particular urban areas based on the urban planning policies of the region. Moreover, in case of existing urban areas, these signatures suggest correlation between form and contexts. Hence, they provide a robust structure for future statistical assessments on climate, energy, economy and social issues to find their relationships with form/density of urban areas. These are the sustainability components that need to be satisfied in order to achieve sustainable cities.

\section{Acknowledgment}

The first author acknowledges the University of Lincoln for funding the $\mathrm{PhD}$ research programme jointly run by Lincoln School of Architecture and the Built Environment in collaboration with Lincoln School of Engineering.

\section{References}

AHMADIAN, E., BYRD, H., SODAGAR, B., MATTHEWMAN, S., KENNEY, C. \& MILLS, G. 2018. Energy and the form of cities: the counterintuitive impact of disruptive technologies. Architectural Science Review, 1-7.

ARBABI, H. \& MAYFIELD, M. 2016. Urban and Rural-Population and Energy Consumption Dynamics in Local Authorities within England and Wales. Buildings, 6, 34.

ARUNDEL, R. \& RONALD, R. 2017. The role of urban form in sustainability of community: The case of Amsterdam. Environment and Planning B: Urban Analytics and City Science, 44, 33-53.

ASCIONE, F., DE MASI, R. F., DE ROSSI, F., FISTOLA, R., SASSO, M. \& VANOLI, G. P. 2013. Analysis and diagnosis of the energy performance of buildings and districts: Methodology, validation and development of Urban Energy Maps. Cities, 35, 270-283.

BAKER, N. \& STEEMERS, K. 2003. Energy and environment in architecture: a technical design guide, Taylor \& Francis.

BERGHAUSER PONT, M. \& HAUPT, P. 2007. The Spacemate: density and the typomorphology of the urban fabric. Urbanism laboratory for cities and regions: progress of research issues in urbanism.

BHIWAPURKAR, P. Determinants of Urban Energy Use: Density and Urban Form. ARCC Conference Repository, 2014.

BYRD, H., HO, A., SHARP, B. \& KUMAR-NAIR, N. 2013. Measuring the solar potential of a city and its implications for energy policy. Energy policy, 61, 944-952.

CHEN, Y.-J., MATSUOKA, R. H. \& LIANG, T.-M. 2018. Urban form, building characteristics, and residential electricity consumption: A case study in Tainan City. Environment and Planning B: Urban Analytics and City Science, 45, 933-952.

CHENG, V. 2009. Understanding density and high density. Designing High-Density Cities. Routledge. 
CHENG, V., STEEMERS, K., MONTAVON, M. \& COMPAGNON, R. Urban form, density and solar potential. PLEA 2006, 2006.

CHURCHMAN, A. 1999. Disentangling the concept of density. Journal of Planning Literature, 13, 389-411.

CLEVENGER, C. M. \& HAYMAKER, J. The impact of the building occupant on energy modeling simulations. Joint International Conference on Computing and Decision Making in Civil and Building Engineering, Montreal, Canada, 2006. Citeseer, 1-10.

COCCOLO, S., MONNA, S., KAEMPF, J. H., MAUREE, D. \& SCARTEZZINI, J.-L. 2016. Energy demand and urban microclimate of old and new residential districts in a hot arid climate.

DCLG 2006. Planning policy statement 3: Housing. Department for Communities and Local Government London.

DENG, W., PENG, Z. \& TANG, Y.-T. 2019. A quick assessment method to evaluate sustainability of urban built environment: Case studies of four large-sized Chinese cities. Cities, 89, 57-69.

DIELEMAN, F. \& WEGENER, M. 2004. Compact city and urban sprawl. Built Environment, 30, 308323.

DOHERTY, M., NAKANISHI, H., BAI, X. \& MEYERS, J. 2009. Relationships between form, morphology, density and energy in urban environments. GEA Background Paper, 28.

DU, P., WOOD, A., DITCHMAN, N. \& STEPHENS, B. 2017. Life Satisfaction of Downtown HighRise vs. Suburban Low-Rise Living: A Chicago Case Study. Sustainability, 9, 1052.

ECHENIQUE, M. H., HARGREAVES, A. J., MITCHELL, G. \& NAMDEO, A. 2012. Growing cities sustainably: does urban form really matter? Journal of the American Planning Association, 78, 121-137.

EMMANUEL, R. \& STEEMERS, K. 2018. Connecting the realms of urban form, density and microclimate. Building Research \& Information.

EWING, R. \& RONG, F. 2008. The impact of urban form on US residential energy use. Housing policy debate, 19, 1-30.

FARRELL, T. 2014. The Farrell review of Architecture+ the Built Environment, our Future in Place. London. http://www.farrellreview.co.uk/downloads/TheFarrellreview.pdf.

GHOSH, S., VALE, R. \& VALE, B. 2006. Domestic energy sustainability of different urban residential patterns: a New Zealand approach. International Journal of Sustainable Development, 9, 1637.

GORDON, I. R., MACE, A. \& WHITEHEAD, C. 2016. Defining, measuring and implementing density standards in London: London plan density research project 1. 2016 Density review. LSE London.

GREENBERG, B. L. 1991. Guidelines for the reurbanisation of Metropolitan Toronto.

HAMILTON, I., EVANS, S., STEADMAN, P., GODOY-SHIMIZU, D., DONN, M., SHAYESTEH, H. \& MORENO, G. 2017. All the way to the top! The energy implications of building tall cities. CISBAT 2017. Switzerland.

HUANG, Y., MUSY, M., HÉGRON, G., CHEN, H. \& LI, B. 2008. 663: Towards urban design guidelines from urban morphology description and climate adaptability.

JAVANROODI, K., MAHDAVINEJAD, M. \& NIK, V. M. 2018. Impacts of urban morphology on reducing cooling load and increasing ventilation potential in hot-arid climate. Applied Energy, 231, 714-746.

JENKS, M. \& DEMPSEY, N. 2005. Future forms and design for sustainable cities, Routledge.

LAI, L. W. \& HO, W. K. 2001. A probit analysis of development control: a Hong Kong case study of residential zones. Urban Studies, 38, 2425-2437.

LEE, G. \& JEONG, Y. 2017. Impact of Urban and Building Form and Microclimate on the Energy Consumption of Buildings-Based on Statistical Analysis. Journal of Asian Architecture and Building Engineering, 16, 565-572.

LINCOLNSHIRE POLICE. 2019. Crime map of Lincoln [Online]. Available: https://www.police.uk/lincolnshire/NC14/crime/+nys7wA/ [Accessed 10 April 2019].

LONGLEY, P. A. \& MESEV, V. 2002. Measurement of density gradients and space-filling in urban systems. Papers in regional science, 81, 1-28.

MARCH, L. 1972. Elementary models of built forms. In: MARTIN, L. \& MARCH, L. (eds.) Urban Space and Structures. Cambridge University Press. 
MARTIN, L. \& MARCH, L. 1972. Urban space and structures, Cambridge University Press.

MATSUMOTO, T., SANCHEZ-SERRA, D. \& OSTRY, A. 2012. Compact city policies: a comparative assessment, OECD.

MCHARG, I. L. 1969. Design with nature, American Museum of Natural History New York.

MOGHADAM, S. T., COCCOLO, S., MUTANI, G., LOMBARDI, P., SCARTEZZINI, J.-L. \& MAUREE, D. 2019. A new clustering and visualization method to evaluate urban heat energy planning scenarios. Cities, 88, 19-36.

MOHAJERI, N., UPADHYAY, G., GUDMUNDSSON, A., ASSOULINE, D., KÄMPF, J. \& SCARTEZZINI, J.-L. 2016. Effects of urban compactness on solar energy potential. Renewable Energy, 93, 469-482.

NEWMAN, P. \& JENNINGS, I. 2012. Cities as sustainable ecosystems: principles and practices, Island Press.

NICHOLS, B. G. \& KOCKELMAN, K. M. 2015. Urban form and life-cycle energy consumption: Case studies at the city scale. Journal of Transport and Land Use, 8, 115-128.

PEPONIS, J., ALLEN, D., FRENCH, S., SCOPPA, M. \& BROWN, J. Street connectivity and urban density. 6th International Space Syntax Symposium Istanbul: ITU Faculty of Architecture, 2007. Citeseer.

PERERA, A., COCCOLO, S., SCARTEZZINI, J.-L. \& MAUREE, D. 2018. Quantifying the impact of urban climate by extending the boundaries of urban energy system modeling. Applied Energy, 222, 847-860.

PLAZA HOMES. 2017. Floor-Area Ratio (FAR) and Building Coverage Ratio (BCR) in Japan [Online]. Tokyo: Tokyo Real Estate News and Information. Available: https://www.realestatetokyo.com/news/floor-area-ratio-and-building-coverage-ratio/ [Accessed 28/10 2018].

R, N. 2014. Why Demographia's data is irrelevant and misleading [Online]. Greater Auckland. Available: $\quad$ https://www.greaterauckland.org.nz/2014/10/28/why-demographia-isfundamentally-wrong/ [Accessed 2018].

RAPOPORT, A. 1975. Toward a redefinition of density. Environment and Behavior, 7, 133-158.

RATTI, C., BAKER, N. \& STEEMERS, K. 2005. Energy consumption and urban texture. Energy and buildings, 37, 762-776.

RATTI, C., RAYDAN, D. \& STEEMERS, K. 2003. Building form and environmental performance: archetypes, analysis and an arid climate. Energy and buildings, 35, 49-59.

RESCH, E., BOHNE, R. A., KVAMSDAL, T. \& LOHNE, J. 2016. Impact of urban density and building height on energy use in cities. Energy Procedia, 96, 800-814.

RODE, P., KEIM, C., ROBAZZA, G., VIEJO, P. \& SCHOFIELD, J. 2014. Cities and energy: urban morphology and residential heat-energy demand. Environment and Planning B: Planning and Design, 41, 138-162.

RUBEL, F. \& KOTTEK, M. 2010. Observed and projected climate shifts 1901-2100 depicted by world maps of the Köppen-Geiger climate classification. Meteorologische Zeitschrift, 19, 135-141.

RUDLIN, D. 2019. Why is Britain so bad at planning cities? The Guardian, 11/04/2019.

SARRALDE, J. J., QUINN, D. J., WIESMANN, D. \& STEEMERS, K. 2015. Solar energy and urban morphology: Scenarios for increasing the renewable energy potential of neighbourhoods in London. Renewable Energy, 73, 10-17.

SCHWARZ, N. 2010. Urban form revisited-Selecting indicators for characterising European cities. Landscape and urban planning, 96, 29-47.

SHARIFI, A. 2019. Resilient urban forms: A macro-scale analysis. Cities, 85, 1-14.

SILVA, M., OLIVEIRA, V. \& LEAL, V. 2017. Urban Form and Energy Demand: A Review of Energyrelevant Urban Attributes. Journal of Planning Literature, 0885412217706900.

STACKEDHOMES. 2018. Plot Ratio - Why you need to know (and how to calculate it) [Online]. StackedHomes. Available: https://stackedhomes.com/blog/plot-ratio-need-know-calculate/ [Accessed 28/10 2018].

STEADMAN, P. 2014a. Building types and built forms, Troubador Publishing Ltd.

STEADMAN, P. 2014b. Density and built form: integrating 'Spacemate'with the work of Martin and March. Environment and Planning B: Planning and Design, 41, 341-358.

STEADMAN, P., EVANS, S. \& BATTY, M. 2009. Wall area, volume and plan depth in the building stock. Building Research \& Information, 37, 455-467. 
STEEMERS, K. 2003. Energy and the city: density, buildings and transport. Energy and buildings, 35, 3-14.

TANG, B.-S. \& TANG, R. M. 1999. Development control, planning incentive and urban redevelopment: evaluation of a two-tier plot ratio system in Hong Kong. Land use policy, 16, 33-43.

TSAI, Y.-H. 2005. Quantifying urban form: compactness versus' sprawl'. Urban studies, 42, 141-161.

UNITED NATIONS 2014. World Urbanization Prospects: The 2014 Revision, Highlights. Population Division. United Nations. 